\title{
Preliminary Options Assessment of Versatile Irradiation Test Reactor
}

Sonat Sen

Giuseppe Palmiotti

Gilles Youinou

Phillip Finck

Massimo Salvatores

January 2017

The INL is a

U.S. Department of Energy

National Laboratory

operated by

Battelle Energy Alliance

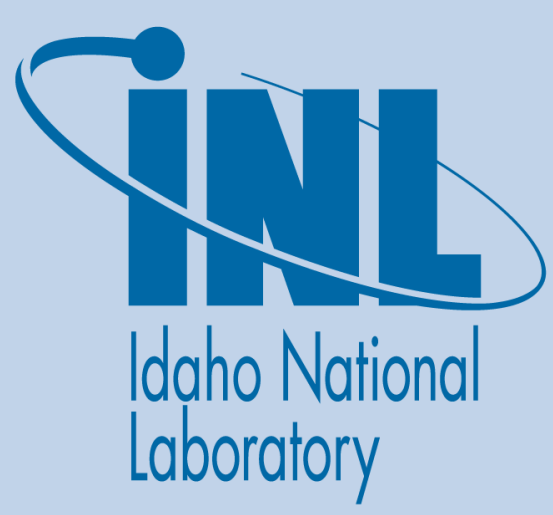




\section{DISCLAIMER}

This information was prepared as an account of work sponsored by an agency of the U.S. Government. Neither the U.S. Government nor any agency thereof, nor any of their employees, makes any warranty, expressed or implied, or assumes any legal liability or responsibility for the accuracy, completeness, or usefulness, of any information, apparatus, product, or process disclosed, or represents that its use would not infringe privately owned rights. References herein to any specific commercial product, process, or service by trade name, trade mark, manufacturer, or otherwise, does not necessarily constitute or imply its endorsement, recommendation, or favoring by the U.S. Government or any agency thereof. The views and opinions of authors expressed herein do not necessarily state or reflect those of the U.S. Government or any agency thereof. 
INL/EXT-16-40780

Revision 0

\title{
Preliminary Options Assessment of Versatile Irradiation Test Reactor
}

\author{
Sonat Sen \\ Giuseppe Palmiotti \\ Gilles Youinou \\ Phillip Finck \\ Massimo Salvatores
}

January 2017

\begin{abstract}
Idaho National Laboratory
INL ART TDO Program

Idaho Falls, Idaho 83415
\end{abstract}

http://www.inl.gov

Prepared for the

U.S. Department of Energy

Office of Nuclear Energy

Under DOE Idaho Operations Office

Contract DE-AC07-05ID14517 



\section{INL ART TDO Program \\ Preliminary Options Assessment of Versatile Irradiation Test Reactor}

INL/EXT-16-40780

Revision 0

January 2017

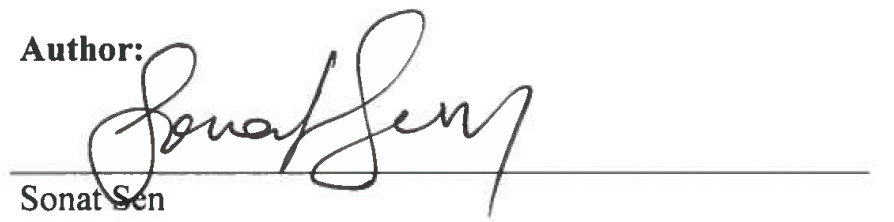

INL ART TDO Staff Scientist/Engineer

$$
01 / 30 / 2017
$$

Date

Technical Reviewer: (Confirmation of mathematical accuracy, and correctness of data and appropriateness of assumptions.)
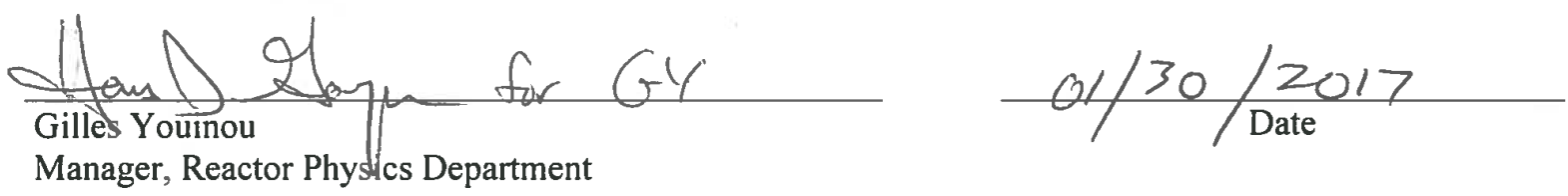

Approved by:

ManeVGar

Diane V. Croson

Deputy Director, INL ART TDO

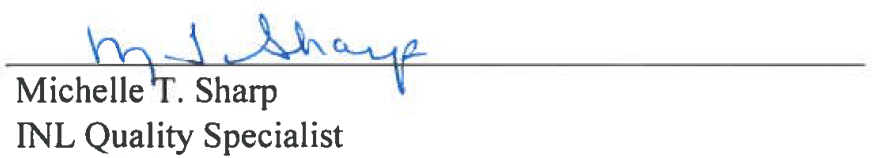

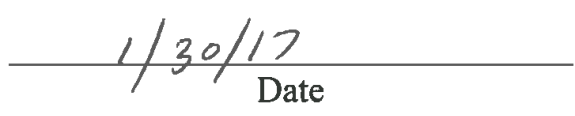

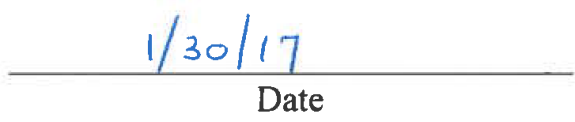




\section{SUMMARY}

The United States has the facilities necessary to meet the nation's need for thermal-neutron irradiations; however, a significant gap exists in the ability to meet the need for fast-neutron irradiations. To ensure the long-term relevance of a new test reactor, the latter should be highly reconfigurable and allow operation as a fast test reactor, a thermal test reactor, or a coupled fast-thermal test reactor in order to satisfy the needs, present and future, of as many customers as possible. In addition to the possibility of generating high-fast and thermalneutron fluxes, the use of sodium as coolant in conjunction with a solid moderator, such as graphite opens the door for such highly reconfigurable cores.

It is important to understand the previous designs and operations of highly configurable cores and fast reactors in order to make smart design choices. Two important reactor designs from the past are considered in the study described in this report. One is the design of the KNK (Compact Sodium Cooled Nuclear Power Plant) that operated in Germany. The KNK design is a good example of having both thermal and fast-neutron spectrum cores within the same vessel, a configuration that provides versatility. The second is the PRISM (Power Reactor Innovative Small Module) fast-neutron-spectrum design by General Electric.

The calculation of displacements per atom for reporting the performance of a test reactor is also provided in this report. The effect of neutron spectrum on the test materials and durations showed the importance of the fast-neutron spectrum for the accelerated material testing.

Several options for the design of a versatile coupled test reactor are considered in the study described in this report. One important finding presented here is that the use of moderator pins in the booster-fuel assemblies of a boostedcore configuration could reduce the amount of fuel needed, while maintaining similar performance. The use of plutonium in the fast zone would provide more flexibility in fuel assembly design than the use of low-enriched uranium. A system-level cost/benefit analysis considering the use of plutonium versus the use of only low-enriched uranium will be necessary in the near future in order to make informed design decisions. 


\section{CONTENTS}

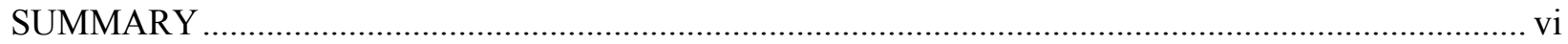

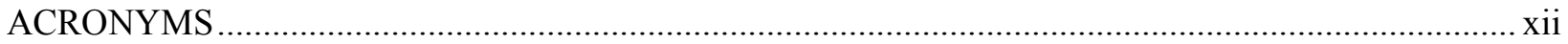

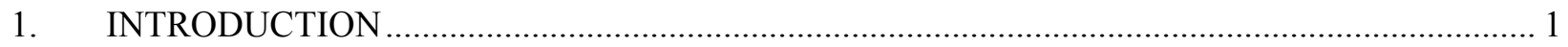

2. PREVIOUS FAST TEST AND POWER REACTOR CONCEPTS …...................................... 1

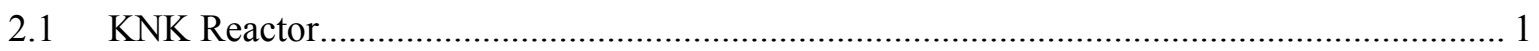

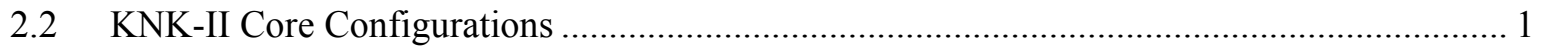

2.2.1 KNK-II First Core

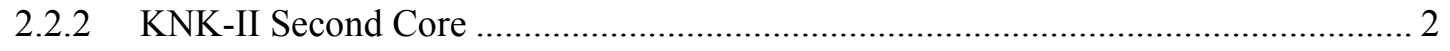

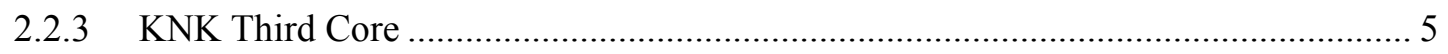

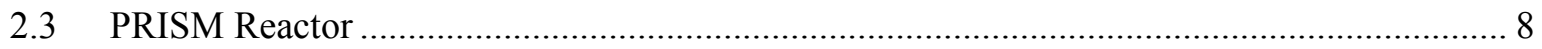

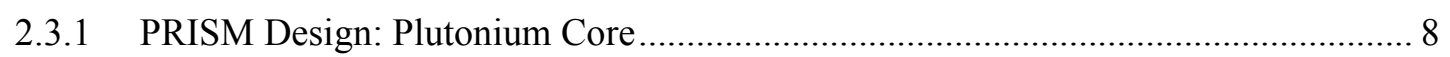

2.3.2 PRISM MOD-A Design: Low-Enriched Uranium Core........................................... 12

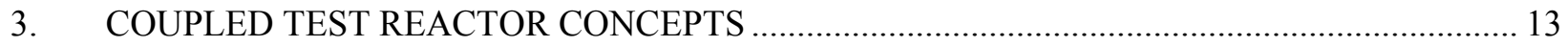

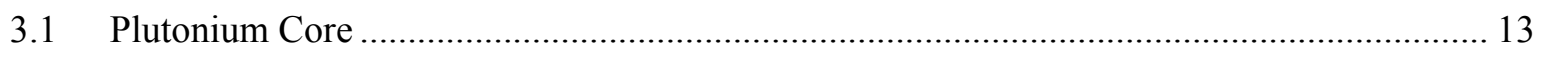

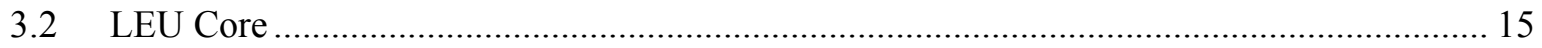

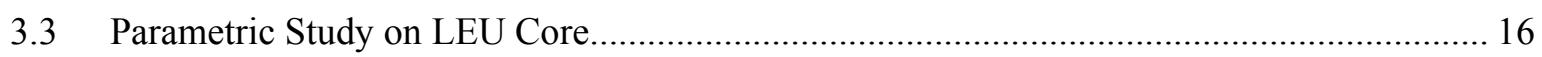

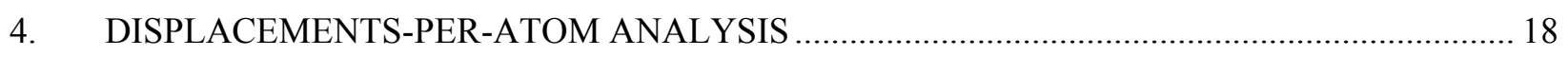

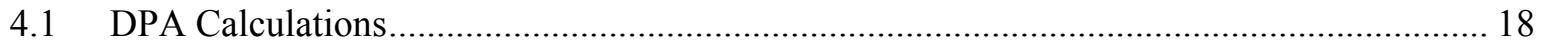

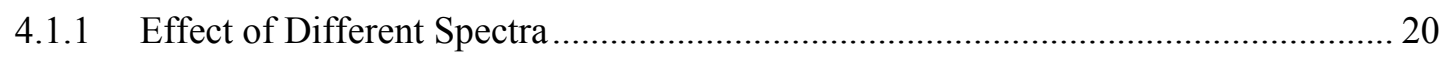

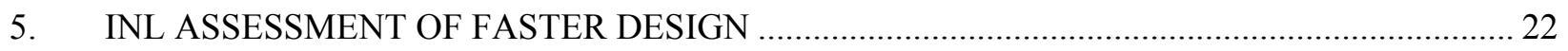

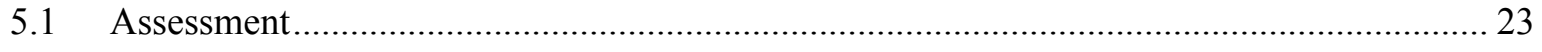

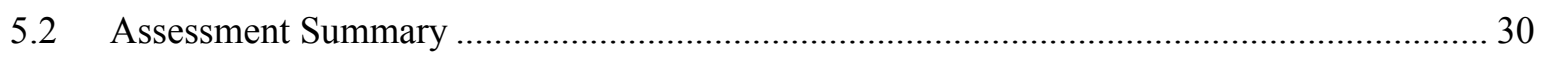

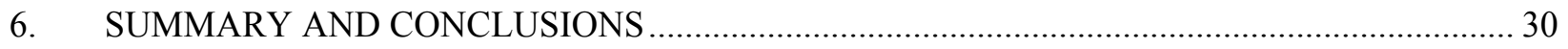

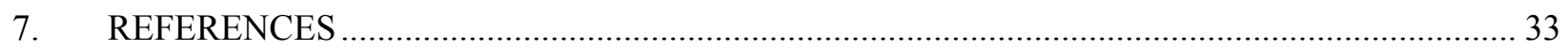

Appendix A The Damage and Gas Production Cross-Section Library Generation for Serpent2

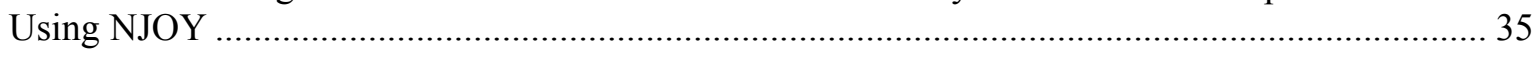

\section{FIGURES}

Figure 1. Plan view of the Serpent2 model of the KNK-II first core configuration. .................................. 2

Figure 2. Elevation view of the Serpent2 model of the KNK-II first core configuration. .......................... 2

Figure 3. Plan view of the Serpent2 model of the KNK-II second core configuration.............................. 3

Figure 4. Elevation view of the Serpent 2 model of the KNK-II second core configuration........................ 4 
Figure 5. Detail view of the fuel assemblies in KNK-II second core configuration................................ 4

Figure 6. Elevation view of the Serpent 2 model of the KNK-II third core configuration.......................... 6

Figure 7. Elevation view of the Serpent 2 model of the KNK-II third core configuration.......................... 6

Figure 8. Detail view of the fuel assemblies in KNK-II third core configuration. .................................... 7

Figure 9. Plan view of the Serpent2 model of the PRISM fast reactor design from References [22]

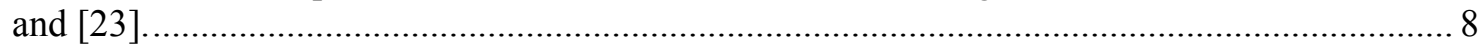

Figure 10. Elevation view (XZ cut) of the Serpent2 model of the PRISM fast reactor design from

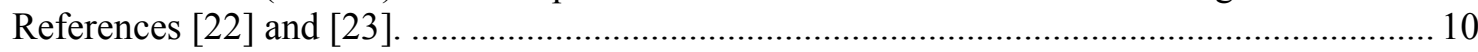

Figure 11. Detailed view of fuel and blanket assemblies in Serpent2 model of the PRISM fast

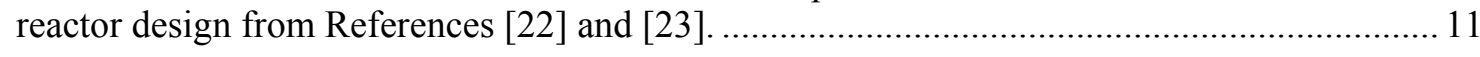

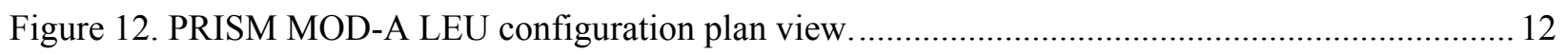

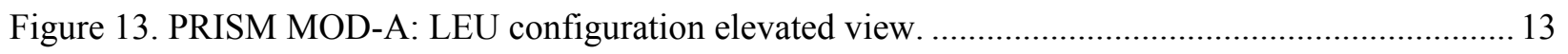

Figure 14. Boosted VCTR concept using plutonium in the fast zone.................................................... 14

Figure 15. Boosted VCTR-LEU concept using neutron moderation within the booster-fuel

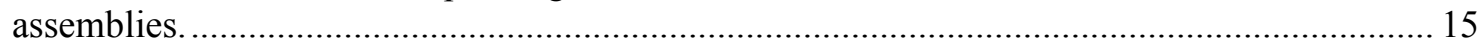

Figure 16. Fast flux radial traverse for the $\operatorname{UZr}(10) 20 \%$ enrichment configuration................................ 17

Figure 17. Relative contributions of the individual iron isotopes to the DPA of stainless steel

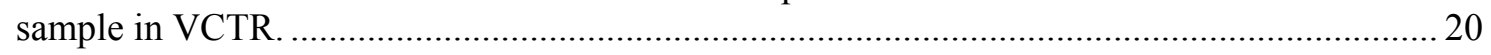

Figure 18. The microscopic damage cross section for different iron isotopes........................................ 20

Figure 19. Super cells used in the DPA analysis for different spectrums: (a) MHTGR, (b) LWR, (c) SFR, and (d) VCTR. All have 0.1-cm-radius solid cylinders made of ${ }^{56} \mathrm{Fe}$ at the center.

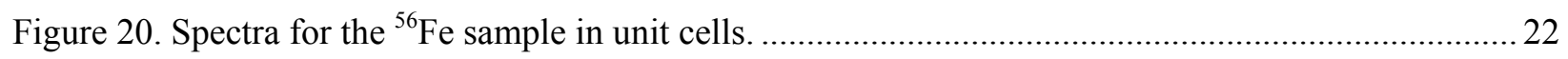

Figure 21. Plan view of the Serpent2 model of the FASTER design....................................................24

Figure 22. Elevation view of the Serpent2 model of the FASTER design. ............................................2 24

Figure 23. Plan view of the Serpent2 model of the FASTER design showing the tally positions.............25

Figure 24. Neutron spectra in different locations shown in Figure 23 .................................................. 26

Figure 25. Fast and thermal-neutron flux map for FASTER design...................................................2 27

Figure 26. Fission power ("hot" shades - red and yellow) and thermal flux ("cold" shades - blue) distribution.

Figure 27. Power peaking factors per pin in the fuel assemblies in Locations B (left) and H (right), as shown in Figure 23.

Figure 28. The axially averaged radial flux profiles tallied in different 30-dgree slices, as shown in Figure 23. 


\section{TABLES}

Table 1. Characteristics of the assemblies used in KNK-II first core configuration....................................2

Table 2. Characteristics of the assemblies used in KNK-II second core configuration............................ 2

Table 3. Characteristics of the assemblies used in KNK-II third core configuration. .............................. 5

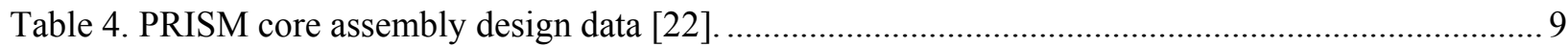

Table 5. Summary of results of PRISM analysis at different compositions........................................... 11

Table 6. Power and main characteristics of the test fast reactor configurations. ...................................... 17

Table 7. Stainless-steel composition and the individual DPA data for the solid cylinder located at

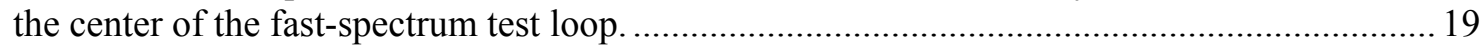

Table 8. DPA results for a solid cylinder of ${ }^{56} \mathrm{Fe}(\mathrm{r}=0.1 \mathrm{~cm})$ at the center of the unit cells................... 22

Table 9. Plutonium vector assumed in the Serpent2 model................................................................. 23

Table 10. Main neutronic parameters for FASTER design calculated with Serpent2 ............................26 


\section{ACRONYMS}

ANL Argonne National Laboratory

ART Advanced Reactor Technologies

ATDR Advanced Test and Demonstration Reactor

DOE U.S. Department of Energy

DPA displacement per atom

GE General Electric

ENDF evaluated nuclear data file

SFR sodium-cooled fast reactor

HM heavy metal

INL Idaho National Laboratory

KNK Compact Sodium Cooled Nuclear Power Plant

LEU low-enriched uranium

LWR light-water reactor

MHTGR modular high-temperature gas-cooled reactor

NRC U.S. Nuclear Regulatory Commission

pcm per cent mille

PRISM Power Reactor Innovative Small Module

VCTR versatile coupled test reactor 


\section{Preliminary Options Assessment of Versatile Irradiation Test Reactor}

\section{INTRODUCTION}

This report summarizes the work undertaken at Idaho National Laboratory (INL) from April 2016 to January 2017 aimed at analyzing some of the options for designing a versatile test reactor; the scope of work was agreed upon with the U.S. Department of Energy (DOE) Office of Nuclear Energy.

Section 2 of this report presents results related to a literature search on the Compact Sodium Cooled Nuclear Power Plant (KNK) and the Power Reactor Innovative Small Module (PRISM) that may aid in designing a versatile test reactor. Section 3 presents alternatives to the versatile coupled test reactor (VCTR) presented in Reference [1], as well as a neutronic parametric study to assess the minimum power requirement needed for a ${ }^{235} \mathrm{U}$-metal-fueled fast-test reactor capable of generating a fast $(>100 \mathrm{keV})$ flux of $4.0 \times 10^{15} \mathrm{n} / \mathrm{cm}^{2}-\mathrm{s}$ at the test location. Section 4 presents results regarding a fundamental characteristic of test reactors, namely displacements per atom (DPAs), in test samples. Section 5 presents the INL assessment of the Argonne National Laboratory (ANL) fast test reactor design, FASTER. Finally, Section 6 summarizes the study described in this report and provides conclusions that were drawn from the study.

\section{PREVIOUS FAST TEST AND POWER REACTOR CONCEPTS}

Understanding the concepts applied in previous fast reactors is important in analyzing the options for designing and building a versatile test reactor. However, much of this information is not readily available. Furthermore, few examples of the VCTR concept can be found in the literature.

This section describes two previous reactor designs whose concepts may aid in designing a versatile test reactor the first design is that used the KNK, and the second is the design used in the PRISM.

\subsection{KNK Reactor}

The KNK project in Germany (1957-1991) was an essential part of the German fast breeder program. The KNK project started with the phase called KNK-I, a pure thermal-neutron sodium-cooled reactor. Information found in the literature is inadequate to analyze KNK-I. However, this reactor was later renamed KNK-II and transitioned to a fast-neutron sodium-cooled reactor with test and driver zone. Unlike KNK-I, a large amount of documentation conducted by the International Atomic Energy Agency on KNK-II is available as a result of experiments. More details regarding KNK-II, the history of the KNK project, and other experiments (STARK, SNEAK, etc.) performed during the German fast breeder reactor program can be found in Reference [2].

The KNK project has little to offer in terms of information regarding a pure coupled reactor. However, the project can be seen as an example of the VCTR "booster" concept with a fast test zone and thermal driver. KNK-II has two significant properties related to VCTR: (1) the demonstration of the transition from a pure thermal reactor to a fast-neutron reactor in the same vessel and (2) the demonstration of the operation of a thermal-neutron reactor with sodium cooling and with a solid zirconium hydride moderator [2].

\subsection{KNK-II Core Configurations}

The transition from KNK-I to KNK-II was performed under the boundary conditions established by the KNK-I plant with respect to its thermal power, coolant flow, and permissible pressure loss $[3,4,5]$. Also, the lattice of the fuel elements and the position of the absorbers were to be adopted from KNK-I, except the central secondary shutdown position was to be replaced by a test element. 
These considerations resulted in a two-zone core with 29 fuel elements producing $58 \mathrm{MW}$ of power. The inner test zone with seven fuel elements was placed to ensure the required test conditions, were met whereas the outer driver zone had to provide enough reactivity for criticality. An additional five blanket elements could be accommodated on the external lattice positions, because the KNK-II core was smaller than the thermal KNK-I core $[3,4,5,6,7]$.

A detailed description of KNK-II core and the assemblies is given in References [3] through [21]. The three core configurations used during KNK-II operation are described in the following subsections.

\subsubsection{KNK-II First Core}

The first core of KNK-II was a two-zone core: (1) a test zone and (2) a driver zone. It also had five breeder elements at the external lattice. The test zone had seven fuel assemblies. The driver zone had six assemblies without moderator elements and 16 assemblies with moderator elements surrounding them. The six control-rod assemblies were located at the third ring with the driver fuel assemblies having no moderator elements $[5,8,9]$.

The characteristics of the assemblies used in the KNK-II first core are given in Table 1. Figure 1 and Figure 2 show the plan and elevation views of the Serpent2 [10] model of the KNK-II first core, respectively. The plutonium content in the test zone is about $25 \%$, while the ${ }^{235} \mathrm{U}$ enrichment is $63 \%$. The test zone fuel assemblies contain 211 fuel pins with six stainless-steel pins at the corners. The driver-zone fuel assemblies without moderator pins consist of 163 fuel pins and six stainless-steel pins at the corners. The driver-zone fuel assemblies with moderator assemblies contain 126 fuel pins, $37 \mathrm{ZrH}_{1.6}$ moderator pins, and six-stainless steel pins at the corners.

Table 1. Characteristics of the assemblies used in KNK-II first core configuration.

\begin{tabular}{|c|c|c|c|c|c|}
\hline \multirow[b]{2}{*}{ Parameter } & \multirow{2}{*}{$\begin{array}{c}\text { Central } \\
\text { Fuel } \\
\text { Assembly }\end{array}$} & \multirow{2}{*}{$\begin{array}{l}\text { Test Zone } \\
\text { Fuel } \\
\text { Assembly }\end{array}$} & \multicolumn{2}{|c|}{ Driver Zone Assembly } & \multirow{2}{*}{$\begin{array}{c}\text { Breeder } \\
\text { Assembly }\end{array}$} \\
\hline & & & Fuel & Moderator & \\
\hline Fuel Type & $\mathrm{PuUO}_{2}$ & $\mathrm{PuUO}_{2}$ & $\mathrm{UO}_{2}$ & $\mathrm{ZrH}_{\mathrm{x}}$ & Depl. $\mathrm{UO}_{2}$ \\
\hline $\begin{array}{l}\text { Fuel Density (\% theoretical } \\
\text { density) }\end{array}$ & 86.5 & 86.5 & 89.6 & - & - \\
\hline $\mathrm{Pu}$ Content (wt $\%)$ & 25 & 26.7 & - & - & - \\
\hline${ }^{235} \mathrm{U}$ Enrichment (wt \%) & 63 & 63.1 & 60 & - & 0.25 \\
\hline Pin Outer Diameter $(\mathrm{cm})$ & 0.6 & 0.6 & 0.82 & 0.82 & 0.915 \\
\hline Pin Inner Diameter $(\mathrm{cm})$ & 0.524 & 0.524 & 0.72 & 0.72 & 0.815 \\
\hline Pellet Diameter $(\mathrm{cm})$ & 0.509 & 0.509 & 0.7 & 0.685 & 0.795 \\
\hline Pin Pitch $(\mathrm{cm})$ & 0.6947 & 0.6947 & 0.88 & 0.88 & 1.039 \\
\hline Duct Pitch $(\mathrm{cm})$ & 12.88 & 12.88 & 12.88 & 12.88 & 12.88 \\
\hline Duct Outer Flat-to-Flat $(\mathrm{cm})$ & 11.0608 & 11.0608 & 12.275 & 12.275 & 12.41 \\
\hline Duct Inner Flat-to-Flat (cm) & 10.461 & 10.461 & 11.755 & 11.755 & 11.89 \\
\hline Number of Pins & 211 & 211 & $163 / 126$ & $0 / 37$ & 121 \\
\hline Pin Height $(\mathrm{cm})$ & 130.9 & 130.9 & 130.9 & 130.9 & 130.9 \\
\hline Fuel Height $(\mathrm{cm})$ & 60 & 60 & 60 & 60 & 99 \\
\hline Upper Breeder Height $(\mathrm{cm})$ & 20 & 20 & - & - & - \\
\hline Lower Breeder Height $(\mathrm{cm})$ & 20 & 20 & - & - & - \\
\hline Top Reflector Height (cm) & - & - & 19 & 47 & - \\
\hline Bottom Reflector Height $(\mathrm{cm})$ & - & - & 19 & 20 & - \\
\hline
\end{tabular}


Table 1. (continued).

\begin{tabular}{|c|c|c|c|c|c|}
\hline \multirow[b]{2}{*}{ Parameter } & \multirow{2}{*}{$\begin{array}{c}\text { Central } \\
\text { Fuel } \\
\text { Assembly }\end{array}$} & \multirow{2}{*}{$\begin{array}{l}\text { Test Zone } \\
\text { Fuel } \\
\text { Assembly }\end{array}$} & \multicolumn{2}{|c|}{ Driver Zone Assembly } & \multirow{2}{*}{$\begin{array}{l}\text { Breeder } \\
\text { Assembly }\end{array}$} \\
\hline & & & Fuel & Moderator & \\
\hline Gas Plenum Height $(\mathrm{cm})$ & 27.1 & 27.1 & 29.1 & - & 29.1 \\
\hline
\end{tabular}

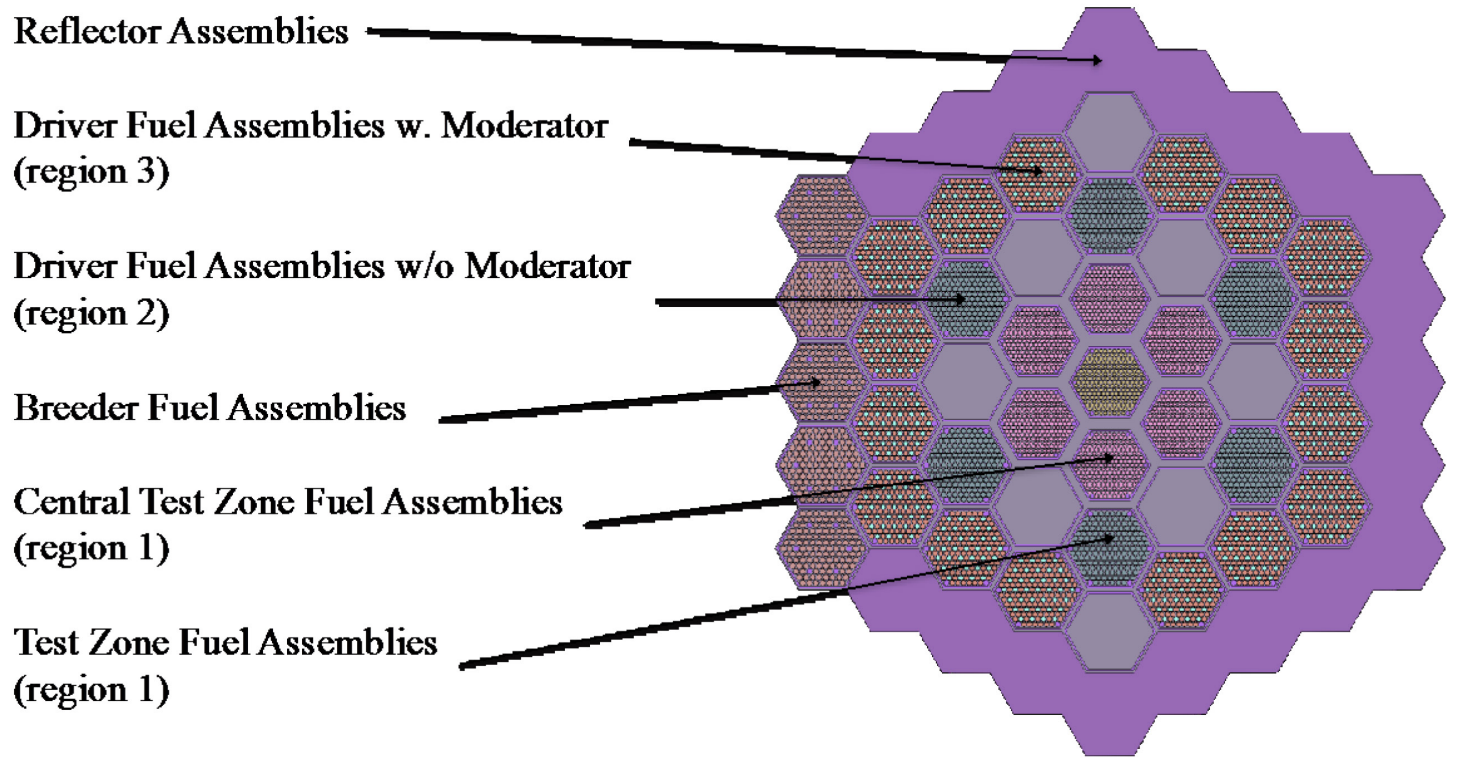

Figure 1. Plan view of the Serpent2 model of the KNK-II first core configuration.

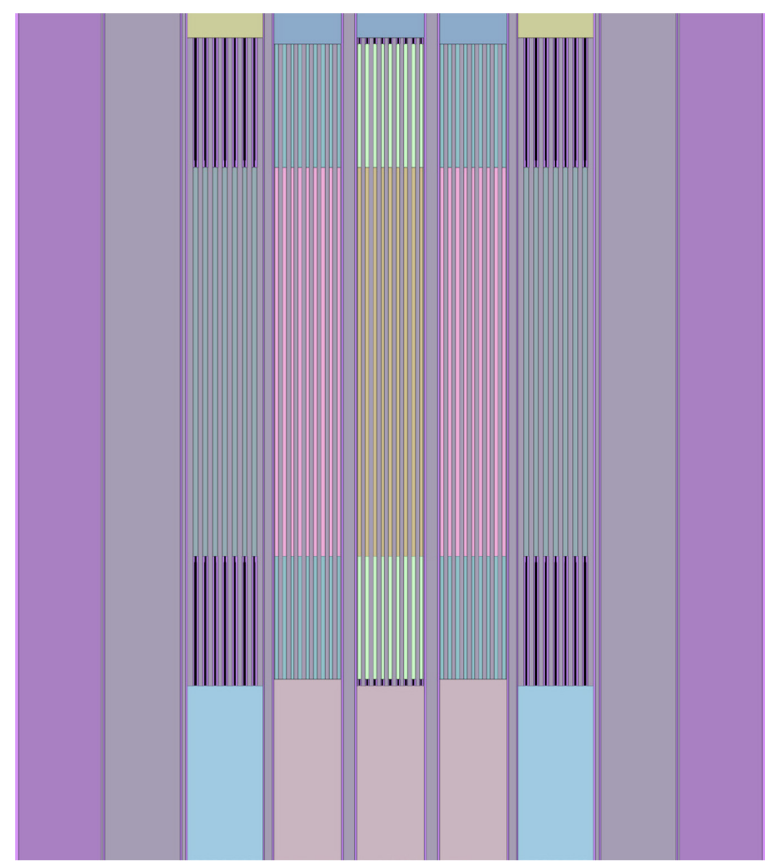

Figure 2. Elevation view of the Serpent2 model of the KNK-II first core configuration. 
The preliminary neutronic analysis was performed with fresh core; note that no depletion calculations were performed. The $\mathrm{k}_{\mathrm{eff}}$ of the fresh core as modeled, is about $1.19753 \pm 0.00097$, and the maximum fast-flux level is about $2.7 \times 10^{15} \mathrm{n} / \mathrm{cm}^{2}$-s occurring at the central test element. The KNK-II first core power peaking factor for the fresh core is about 1.2, and the maximum power density at the central test location is about $820 \mathrm{~W} / \mathrm{cm}^{3}$. Note that the results shown here do not represent the actually operated KNK-II first core. However, these results can be used to inform a new test reactor design such as VCTR.

Avery's coupling coefficients [11] are calculated with the modified version of Serpent2 code [12]. The test zone is assigned as Region 1, whereas the driver zones without moderator pins and with moderator pins are assigned as Regions 2 and 3, respectively. The calculated coupling coefficients are:

$$
\left[\begin{array}{lll}
k_{11} & k_{12} & k_{13} \\
k_{21} & k_{22} & k_{23} \\
k_{31} & k_{32} & k_{33}
\end{array}\right]=\left[\begin{array}{lll}
0.9135 \pm 0.0023 & 0.1727 \pm 0.0049 & 0.3342 \pm 0.0035 \\
0.3324 \pm 0.0061 & 0.3355 \pm 0.0061 & 0.4874 \pm 0.0047 \\
0.1684 \pm 0.0054 & 0.1415 \pm 0.0055 & 0.6629 \pm 0.0027
\end{array}\right]
$$

where $k_{i j}$ represents the average number of next-generation fission neutrons that Region $i$ caused by a single fission neutron born in Region $j$. From the Avery's coupling coefficients, it can be deduced that the test zone is the most reactive zone, as expected due to the plutonium content. The moderator pins increase the reactivity of the driver zone. The neutrons born in Region 3 cause more fission in Region 2 than the neutrons born in Region 2, i.e., 0.3 compared to 0.5 .

\subsubsection{KNK-II Second Core}

The test zone of the KNK-II second core had seven fuel assemblies, whereas the driver zone had six assemblies without moderator elements and 16 assemblies with moderator elements surrounding them. The six control rod assemblies were located at the third ring with the driver fuel assemblies having no moderator elements $[13,14,15,16]$. The central test zone assembly was located inside a stainless-steel cylinder.

The characteristics of the assemblies used in the KNK-II second core are given in Table 2. Figure 3 and Figure 4 illustrate the plan and elevation views of the Serpent 2 model of the KNK-II second core, respectively. Figure 5 shows the details of the fuel assemblies as modeled in Serpent2.

The plutonium content in the test zone is about $25 \%$, while the ${ }^{235} \mathrm{U}$ enrichment is $63 \%$, similar to the first core. The ${ }^{235} \mathrm{U}$ enrichments for the driver-zone fuel assemblies with and without moderator pins are 60 and $40 \%$, respectively. The central test-zone fuel assembly contains 120 fuel pins with seven stainlesssteel pins at the center and the corners, while the other six test-zone fuel assemblies contain 127 fuel pins. The driver-zone fuel assemblies without moderator pins consist of 163 fuel pins and six stainless-steel pins at the corners. The driver-zone fuel assemblies with moderator assemblies contain 126 fuel pins, $37 \mathrm{ZrH}_{1.6}$ moderator pins, and six stainless-steel pins at the corners.

Table 2. Characteristics of the assemblies used in KNK-II second core configuration.

\begin{tabular}{|c|c|c|c|c|c|}
\hline \multirow[b]{2}{*}{ Parameter } & \multirow{2}{*}{$\begin{array}{c}\text { Central } \\
\text { Fuel } \\
\text { Assembly }\end{array}$} & \multirow{2}{*}{$\begin{array}{l}\text { Test Zone } \\
\text { Fuel } \\
\text { Assembly }\end{array}$} & \multicolumn{2}{|c|}{ Driver Zone Assembly } & \multirow[b]{2}{*}{$\begin{array}{l}\text { Breeder } \\
\text { Assembly }\end{array}$} \\
\hline & & & Fuel & Moderator & \\
\hline Fuel Type & $\mathrm{PuUO}_{2}$ & $\mathrm{PuUO}_{2}$ & $\mathrm{UO}_{2}$ & $\mathrm{ZrH}_{\mathrm{x}}$ & Depl. $\mathrm{UO}_{2}$ \\
\hline $\begin{array}{l}\text { Fuel Density (\% theoretical } \\
\text { density) }\end{array}$ & 94 & 92 & 90 & 100 & 95 \\
\hline Pu Content (wt $\%)$ & 24 & 26.7 & - & - & - \\
\hline${ }^{235} \mathrm{U}$ Enrichment (wt\%) & 63 & 63.1 & $60 / 40$ & - & - \\
\hline Pin Outer Diameter $(\mathrm{cm})$ & 0.76 & 0.76 & 0.76 & 0.76 & 0.915 \\
\hline Pin Inner Diameter (cm) & 0.66 & 0.66 & 0.66 & 0.66 & 0.815 \\
\hline
\end{tabular}


Table 2. (continued).

\begin{tabular}{|c|c|c|c|c|c|}
\hline \multirow[b]{2}{*}{ Parameter } & \multirow{2}{*}{$\begin{array}{c}\text { Central } \\
\text { Fuel } \\
\text { Assembly }\end{array}$} & \multirow{2}{*}{$\begin{array}{l}\text { Test Zone } \\
\text { Fuel } \\
\text { Assembly }\end{array}$} & \multicolumn{2}{|c|}{ Driver Zone Assembly } & \multirow{2}{*}{$\begin{array}{c}\text { Breeder } \\
\text { Assembly }\end{array}$} \\
\hline & & & Fuel & Moderator & \\
\hline Pellet Diameter $(\mathrm{cm})$ & 0.638 & 0.641 & 0.641 & 0.641 & 0.795 \\
\hline Pin Pitch $(\mathrm{cm})$ & 0.88 & 0.88 & 0.88 & 0.88 & 1.039 \\
\hline Duct Pitch $(\mathrm{cm})$ & 12.88 & 12.88 & 12.88 & 12.88 & 12.88 \\
\hline Duct Outer Flat-to-Flat $(\mathrm{cm})$ & 11.0608 & 11.0608 & 12.275 & 12.275 & 12.41 \\
\hline Duct Inner Flat-to-Flat $(\mathrm{cm})$ & 10.225 & 10.225 & 11.755 & 11.755 & 11.89 \\
\hline Number of Pins & 120 & 127 & $163 / 126$ & $0 / 37$ & 121 \\
\hline Pin Height $(\mathrm{cm})$ & 130.9 & 130.9 & 130.9 & 130.9 & 130.9 \\
\hline Fuel Height $(\mathrm{cm})$ & 60 & 60 & 60 & 60 & 99 \\
\hline Upper Breeder Height $(\mathrm{cm})$ & 20 & 20 & - & - & - \\
\hline Lower Breeder Height $(\mathrm{cm})$ & 20 & 20 & - & - & - \\
\hline Top Reflector Height (cm) & - & - & 19 & 47 & - \\
\hline Bottom Reflector Height $(\mathrm{cm})$ & - & - & 19 & 20 & - \\
\hline Gas Plenum Height $(\mathrm{cm})$ & 27.1 & 27.1 & 29.1 & - & 29.1 \\
\hline
\end{tabular}

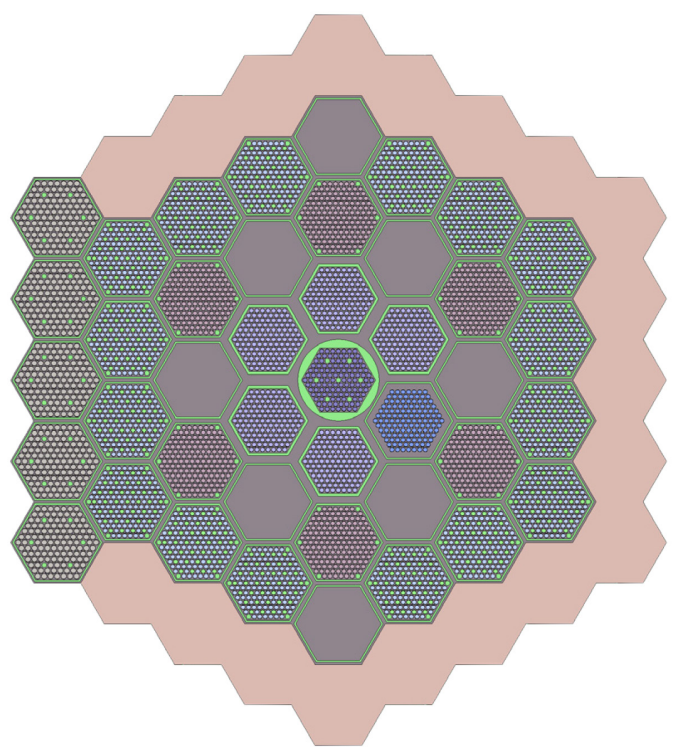

Figure 3. Plan view of the Serpent2 model of the KNK-II second core configuration. 


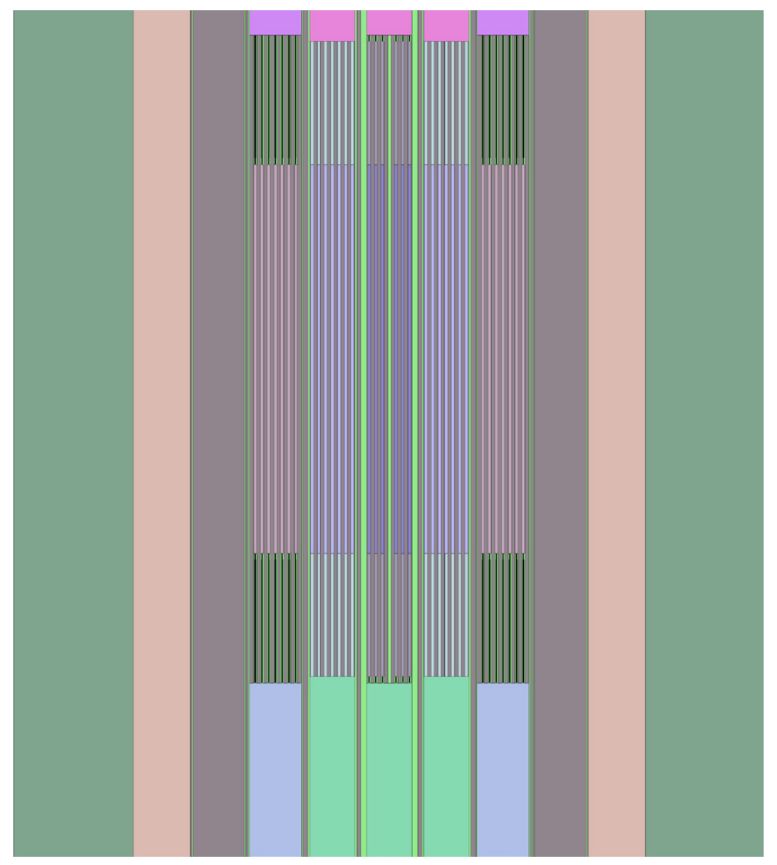

Figure 4. Elevation view of the Serpent2 model of the KNK-II second core configuration.

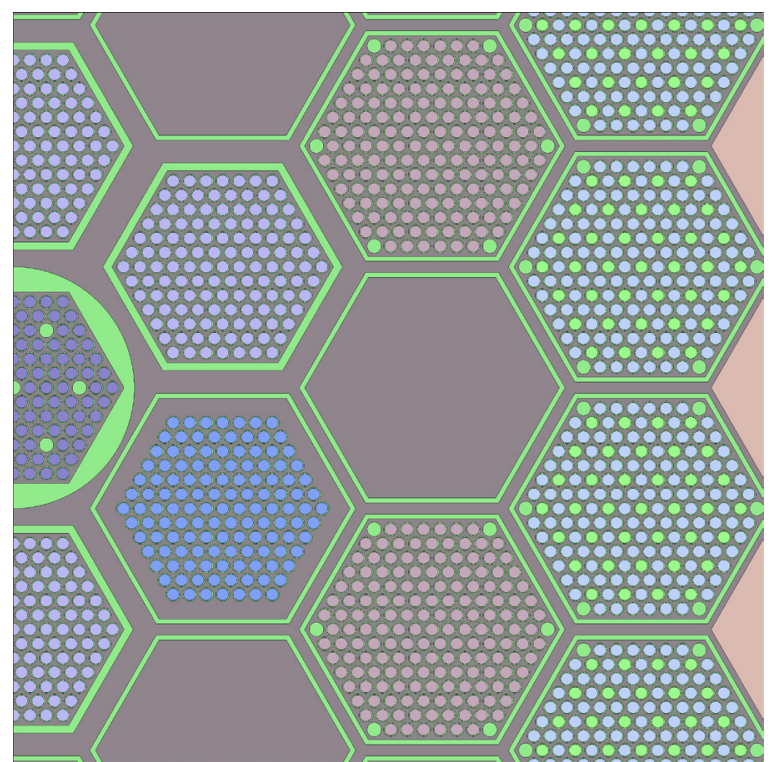

Figure 5. Detail view of the fuel assemblies in KNK-II second core configuration.

The preliminary neutronic analysis was performed with fresh core; note that no depletion calculations were performed. The $\mathrm{k}_{\mathrm{eff}}$ of the fresh core, as modeled is about $1.13374 \pm 0.00004$, and the maximum fast flux level is about $2.5 \times 10^{15} \mathrm{n} / \mathrm{cm}^{2}$-s, occurring at the central test element. The power peaking of the second core of KNK-II is not as high as the first core power peaking factor for the fresh core, which is about 1.08 and the peak power density occurring at the test-zone fuel assembly, No. 205, is about $600 \mathrm{~W} / \mathrm{cm}^{3}$. Note that the results shown here do not represent the real operated KNK-II second core. However, these results can be used for optimizing a new test reactor design such as VCTR. 
Avery's coupling coefficients are calculated with the modified version of Serpent 2 code. The test zone is assigned as Region 1, whereas the driver zones without moderator pins and with moderator pins are assigned as Regions 2 and Region 3, respectively. The calculated coupling coefficients are:

$\left[\begin{array}{lll}k_{11} & k_{12} & k_{13} \\ k_{21} & k_{22} & k_{23} \\ k_{31} & k_{32} & k_{33}\end{array}\right]=\left[\begin{array}{lll}0.7494 \pm 0.0001 & 0.2350 \pm 0.0002 & 0.3548 \pm 0.0002 \\ 0.2636 \pm 0.0002 & 0.4134 \pm 0.0002 & 0.4782 \pm 0.0002 \\ 0.1389 \pm 0.0002 & 0.1834 \pm 0.0002 & 0.6481 \pm 0.0001\end{array}\right]$

where $k_{i j}$ represents the average number of next-generation fission neutrons that Region $i$ caused by a single fission neutron born in Region $j$. From the Avery's coupling coefficients, it can be deduced that the test zone is the most reactive zone, as expected due to the plutonium content. The moderator pins increase the reactivity of the driver zone. The neutrons born in Region 3 cause more fission in Region 2 than the neutrons born in Region 2, i.e., 0.4 compared to 0.48, even though the Region 3 fuel enrichment is $30 \%$ lower than the Region 2 fuel.

\subsubsection{KNK Third Core}

The test zone of the KNK-II third core had seven fuel assemblies, whereas the driver zone had six assemblies without moderator elements and 16 assemblies with moderator elements surrounding them. The six control-rod assemblies were located at the third ring with the driver fuel assemblies having no moderator elements $[17,18,19,20,21]$. The central test-zone assembly and test-zone assembly No. 205 had empty space for test assemblies.

The characteristics of the assemblies used in the KNK-II third core are given in Table 3. Figure 6 and Figure 7 illustrate the plan and elevation views of the Serpent 2 model of the KNK-II third core, respectively. Figure 8 shows the details of the fuel assemblies as modeled in Serpent 2.

Table 3. Characteristics of the assemblies used in KNK-II third core configuration.

\begin{tabular}{|c|c|c|c|c|c|}
\hline \multirow[b]{2}{*}{ Parameter } & \multirow{2}{*}{$\begin{array}{l}\text { Central } \\
\text { Fuel } \\
\text { Assembly }\end{array}$} & \multirow{2}{*}{$\begin{array}{l}\text { Test Zone } \\
\text { Fuel } \\
\text { Assembly }\end{array}$} & \multicolumn{2}{|c|}{ Driver Zone Assembly } & \multirow{2}{*}{$\begin{array}{l}\text { Breeder } \\
\text { Assembly }\end{array}$} \\
\hline & & & Fuel & Moderator & \\
\hline Fuel Type & $\mathrm{PuUO}_{2}$ & $\mathrm{PuUO}_{2}$ & $\mathrm{UO}_{2}$ & $\mathrm{ZrHx}$ & Depl. $\mathrm{UO}_{2}$ \\
\hline $\begin{array}{l}\text { Fuel Density (\% theoretical } \\
\text { density) }\end{array}$ & 94 & 94 & 90 & 100 & 95 \\
\hline $\mathrm{Pu}$ Content (wt $\%)$ & 28 & 28 & - & - & - \\
\hline${ }^{235} \mathrm{U}$ Enrichment (wt\%) & 73 & 73 & $60 / 50$ & - & - \\
\hline Pin Outer Diameter $(\mathrm{cm})$ & 0.76 & 0.76 & 0.76 & 0.76 & 0.915 \\
\hline Pin Inner Diameter $(\mathrm{cm})$ & 0.66 & 0.66 & 0.66 & 0.66 & 0.815 \\
\hline Pellet Diameter $(\mathrm{cm})$ & 0.637 & 0.637 & 0.641 & 0.641 & 0.795 \\
\hline Pin Pitch $(\mathrm{cm})$ & 0.88 & 0.88 & 0.88 & 0.88 & 1.039 \\
\hline Duct Pitch $(\mathrm{cm})$ & 12.88 & 12.88 & 12.88 & 12.88 & 12.88 \\
\hline Duct Outer Flat-to-Flat (cm) & 11.0608 & 11.0608 & 12.275 & 12.275 & 12.41 \\
\hline Duct Inner Flat-to-Flat (cm) & 10.225 & 10.225 & 11.755 & 11.755 & 11.89 \\
\hline Number of Pins & 108 & $127 / 102$ & $163 / 126$ & $0 / 37$ & 121 \\
\hline Pin Height $(\mathrm{cm})$ & 130.9 & 130.9 & 130.9 & 130.9 & 130.9 \\
\hline Fuel Height $(\mathrm{cm})$ & 55 & 60 & 60 & 60 & 99 \\
\hline Upper Breeder Height $(\mathrm{cm})$ & 20 & 20 & - & - & - \\
\hline Lower Breeder Height $(\mathrm{cm})$ & 20 & 20 & - & - & - \\
\hline
\end{tabular}


Table 3. (continued).

\begin{tabular}{|c|c|c|c|c|c|}
\hline \multirow[b]{2}{*}{ Parameter } & \multirow{2}{*}{$\begin{array}{c}\text { Central } \\
\text { Fuel } \\
\text { Assembly }\end{array}$} & \multirow{2}{*}{$\begin{array}{l}\text { Test Zone } \\
\text { Fuel } \\
\text { Assembly }\end{array}$} & \multicolumn{2}{|c|}{ Driver Zone Assembly } & \multirow{2}{*}{$\begin{array}{c}\text { Breeder } \\
\text { Assembly }\end{array}$} \\
\hline & & & Fuel & Moderator & \\
\hline Top Reflector Height $(\mathrm{cm})$ & - & - & 19 & 47 & - \\
\hline Bottom Reflector Height $(\mathrm{cm})$ & - & - & 19 & 20 & - \\
\hline Gas Plenum Height $(\mathrm{cm})$ & 27.1 & 27.1 & 29.1 & - & 29.1 \\
\hline
\end{tabular}

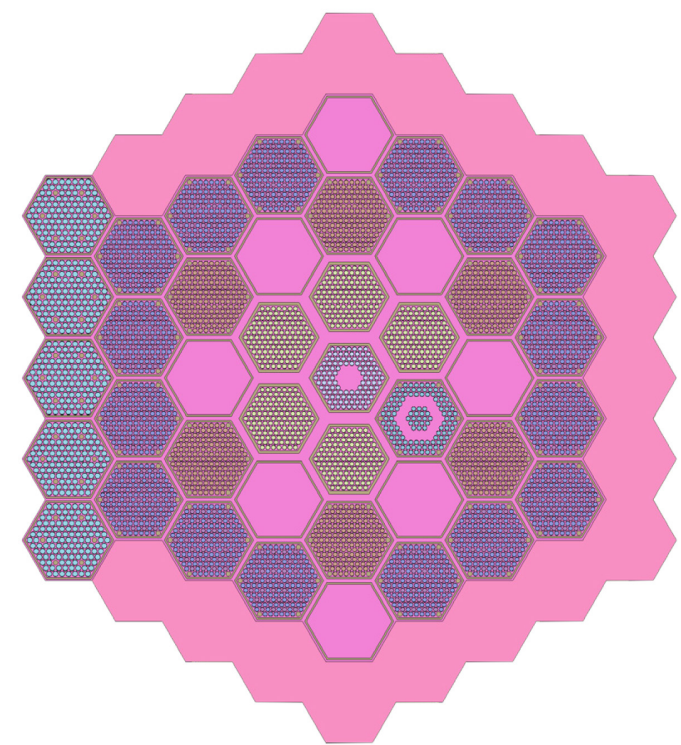

Figure 6. Elevation view of the Serpent 2 model of the KNK-II third core configuration.

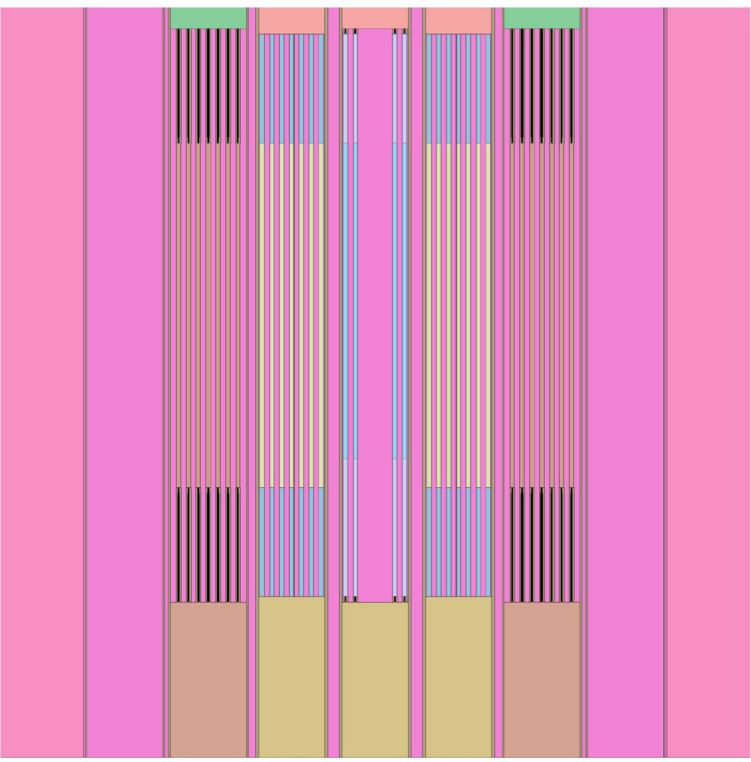

Figure 7. Elevation view of the Serpent 2 model of the KNK-II third core configuration. 


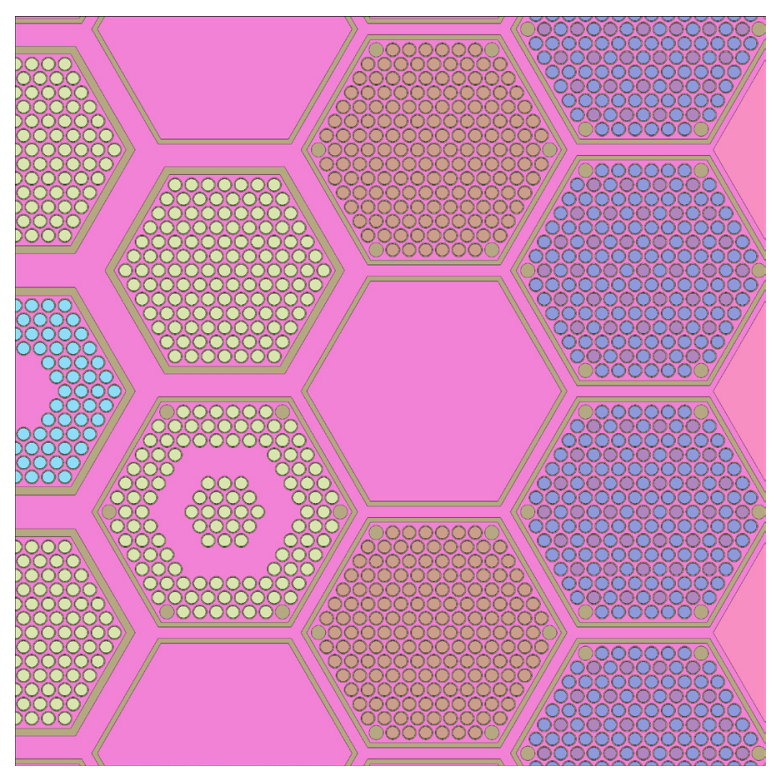

Figure 8. Detail view of the fuel assemblies in KNK-II third core configuration.

The plutonium content in the test zone is $28 \%$, while the ${ }^{235} \mathrm{U}$ enrichment is $73 \%$. The ${ }^{235} \mathrm{U}$ enrichment for the driver-zone fuel assemblies with and without moderator pins is 60 and $50 \%$, respectively. The central test-zone fuel assembly contains 108 fuel pins. The other five test-zone fuel assemblies contain 127 fuel pins, while test-zone fuel assembly No. 205 has 102 fuel pins and six stainless-steel pins at the corners. The driver-zone fuel assemblies without moderator pins consist of 163 fuel pins and six stainless-steel pins at the corners. The driver-zone fuel assemblies with moderator assemblies contain 126 fuel pins, $37 \mathrm{ZrH}_{1.6}$ moderator pins, and six stainless-steel pins at the corners.

The preliminary neutronic analysis was performed with fresh core; note that no depletion calculations were performed. The $\mathrm{k}_{\mathrm{eff}}$ of the fresh core as modeled is about $1.13208 \pm 0.00037$, and the maximum fastflux level is about $2.3 \times 10^{15} \mathrm{n} / \mathrm{cm}^{2}$-s occurring at the central test element. The power peaking of the third core of KNK-II is similar to that of second core for the fresh core, which is about 1.11. The peak power density occurring at test-zone fuel assembly No. 206 is about $610 \mathrm{~W} / \mathrm{cm}^{3}$. Note that the results shown here do not represent the actually operated KNK-II third core.

Avery's coupling coefficients are calculated with the modified version of Serpent 2 code. The test zone is assigned as Region 1, whereas the driver zones without moderator pins and with moderator pins are assigned as Regions 2 and 3, respectively. The calculated coupling coefficients are:

$\left[\begin{array}{lll}k_{11} & k_{12} & k_{13} \\ k_{21} & k_{22} & k_{23} \\ k_{31} & k_{32} & k_{33}\end{array}\right]=\left[\begin{array}{lll}0.7460 \pm 0.0011 & 0.2354 \pm 0.0019 & 0.3566 \pm 0.0015 \\ 0.2627 \pm 0.0021 & 0.4129 \pm 0.0017 & 0.4778 \pm 0.0015 \\ 0.1381 \pm 0.0021 & 0.1834 \pm 0.0018 & 0.6492 \pm 0.0010\end{array}\right]$

where $k_{i j}$ represents the average number of next-generation fission neutrons that Region $i$ caused by a single fission neutron born in Region $j$. From the Avery's coupling coefficients, it can be deduced that the test zone is the most reactive zone, as expected due to the plutonium content. The moderator pins increase the reactivity of the driver zone. The neutrons born in Region 2 cause more fission in Region 2 than the neutrons born in Region 2, i.e., 0.41 compared to 0.48, even though the Region 3 fuel enrichment is lower than the Region 2 fuel enrichment.

The effect of the solid moderator pins is quantified by analyzing the KNK-II third core by simply replacing the $\mathrm{ZrH}_{1.6}$ with stainless steel, i.e., no moderation within the driver fuel assemblies. The resulting $\mathrm{k}_{\mathrm{eff}}$ of the fresh core is $1.09801 \pm 0.00013$. Thus, the effect of the moderation within the driver 
fuel assemblies is about 3,500 per cent mille (pcm), which confirms the conclusions derived from the Avery's coupling coefficients.

\subsection{PRISM Reactor}

The PRISM power plant is a sodium-cooled fast-neutron spectrum reactor designed by General Electrics (GE). An extensive U.S. Nuclear Regulatory Commission (NRC) pre-application review was performed on the PRISM design between 1987 and 1994 [22,23]. The PRISM reactor design that underwent the NRC pre-application review employs UPuZr alloy metal fuel with internal and radial blankets. During the DOE Advanced Test and Demonstration Reactor (ATDR) study conducted in 2015 and 2016, GE Hitachi presented a sodium-cooled fast-reactor (PRISM MOD-A) concept based on the original PRISM design. This design supports all of the most promising fuel cycles identified in the recent multi-year DOE fuel cycle evaluation and screening study [24]. It is suggested that PRISM demonstration reactor would start up on UZr fuel and can be followed by UPuZr fuel.

There is not enough design information found in Reference [24] for a simple Serpent2 analysis; therefore, the earlier PRISM design from References [22] and [23] was analyzed first to develop the heterogeneous Serpent2 models.

\subsubsection{PRISM Design: Plutonium Core}

The reference PRISM core consists of 42 fuel assemblies, 24 internal and 33 radial blanket assemblies, 60 removable radial shield assemblies, six control and one ultimate shutdown assemblies, and three gas-expansion module assemblies. Figure 9 illustrates the plan view of the Serpent 2 model of the PRISM design. Note that the control and ultimate shutdown assemblies, as well as the gas-expansion modules, are filled with sodium in the model.

The core is designed to produce $425 \mathrm{MWt}$ with refueling intervals of about 18 to 20 months $[22,23]$. The design uses $\mathrm{U}-26 \% \mathrm{Pu}-10 \% \mathrm{Zr}$ in the fuel assemblies and depleted $\mathrm{U}-10 \% \mathrm{Zr}$ in the blanket assemblies. The core structural material is HT9. The details of the assembly design in cold conditions (as fabricated) are summarized in Table 4 . The fresh core contains about 5 tons of $\mathrm{U}-26 \% \mathrm{Pu}-10 \% \mathrm{Zr}$ alloy (of which 1.3 tons is plutonium and 3.2 tons is uranium), and it contains about 10 tons of depleted uranium.

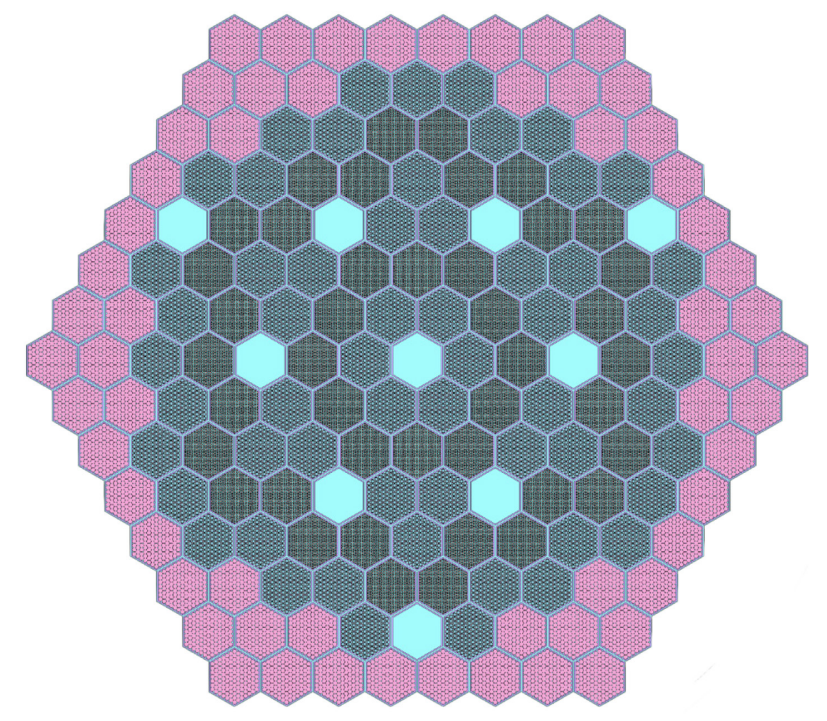

Figure 9. Plan view of the Serpent2 model of the PRISM fast reactor design from References [22] and [23]. 
Table 4. PRISM core assembly design data [22].

\begin{tabular}{|c|c|c|c|}
\hline Parameter & Fuel Assembly & Blanket Assembly & Shield Assembly \\
\hline Duct Pitch $(\mathrm{cm})$ & 15.96 & 15.96 & 15.96 \\
\hline Duct Outer Flat-to-Flat $(\mathrm{cm})$ & 15.51 & 15.51 & 15.51 \\
\hline Duct Inner Flat-to-Flat (cm) & 14.80 & 14.80 & 14.80 \\
\hline Pins Per Assembly & 271 & 127 & 127 \\
\hline Pin Outer Diameter $(\mathrm{cm})$ & 0.74 & 1.21 & 1.29 \\
\hline Clad Thickness $(\mathrm{cm})$ & 0.06 & 0.06 & - \\
\hline Fuel Diameter $(\mathrm{cm})$ & 0.54 & 1.01 & - \\
\hline Pin Pitch-to-Diameter Ratio & 1.199 & 1.069 & 1.0063 \\
\hline Fuel Type & $\mathrm{U}-\mathrm{Pu}-10 \% \mathrm{Zr}$ & Depl. U-10\%Zr & HT9 \\
\hline Cladding Material & HT9 & HT9 & - \\
\hline Duct Material & HT9 & HT9 & HT9 \\
\hline Assembly Length $(\mathrm{cm})$ & 472.44 & 472.44 & 472.44 \\
\hline Pin Height $(\mathrm{cm})$ & 401.32 & 401.32 & 401.32 \\
\hline Fuel Height $(\mathrm{cm})$ & 119.38 & 119.38 & - \\
\hline Upper Gas Plenum Height $(\mathrm{cm})$ & 177.80 & 177.80 & - \\
\hline Lower Shielding Height $(\mathrm{cm})$ & 101.60 & 101.60 & - \\
\hline Upper Plug Height $(\mathrm{cm})$ & 2.54 & 2.54 & - \\
\hline $\begin{array}{l}\text { Fuel Fabrication Density (\% theoretical } \\
\text { density) }\end{array}$ & 100.00 & 100.00 & - \\
\hline $\begin{array}{l}\text { Fuel Smear Density (\% theoretical } \\
\text { density) }\end{array}$ & 75.00 & 85.00 & - \\
\hline Fuel Vol\% & 28.22 & 46.16 & - \\
\hline Coolant Vol\% & 46.72 & 33.42 & 16.22 \\
\hline Structure Vol\% & 25.06 & 20.42 & 83.78 \\
\hline
\end{tabular}

The PRISM fuel assembly contains 271 fuel pins containing U-Pu- $10 \% \mathrm{Zr}$ metal alloy. Neutron and gamma shielding is provided above and below the core in the form of end plugs and a fission gas plenum. The fuel pins do not include any axial blanket zones above or below the core. The only breeding is in the internal and radial blankets. The active core is about $120 \mathrm{~cm}$ tall, and the gas plenum above the fuel is about $178 \mathrm{~cm}$ tall, which sufficiently allows the sodium bonding between the fuel and the clad. The fuel smear density is $75 \%$. The blanket assemblies contain 127 pins. The active breeding section contains depleted U-10\%Zr alloy with a smear density of $85 \%$. The axial length of active fuel, gas plenum, and lower shielding are same as the axial length of the fuel pin. The shield assemblies contain 127 solid HT9 rods with an overall length that is the same as fuel pin length. The elevation view of the Serpent 2 model is shown in Figure 10.

The volume fraction of the fuel is about $28 \%$ in the fuel assemblies, whereas it is about $46 \%$ in the blanket assemblies. The coolant volume fraction is about 47 and $33 \%$ in fuel and blanket assemblies, respectively. The coolant volume fraction in the shielding assemblies is about $16 \%$. Figure 11 illustrates all the detail of the driver and blanket assemblies as modeled in Serpent 2 code. The relative size of the driver and blanket pins, as well as the volume fractions in these assemblies, can be seen in Figure 11.

The calculated $\mathrm{k}_{\text {eff }}$ of the fresh core is $0.99468 \pm 0.00047$. Note that the breeder assemblies contain only depleted uranium, i.e. there is no plutonium present in these assemblies in the case of fresh core. The maximum flux is about $2.0 \times 10^{15} \mathrm{n} / \mathrm{cm}^{2}$-s. The peak linear power in the fissile core is about $37 \mathrm{~kW} / \mathrm{m}$. 
The power fraction in the fissile core is $91 \%$, whereas it is $9 \%$ in the internal and radial blankets for the fresh core.

Note that the results shown above are for the fresh core. The presence of the internal and radial blankets affects the fraction of power produced in the driver-fuel region during the depletion cycle. It is reported in Reference [22] that the fraction of power produced in the driver-fuel region starts at $72 \%$ at the beginning of equilibrium cycle and drops to $65 \%$ at the end. The detailed depletion analysis, including fuel shuffling, etc., is beyond the scope of this study; therefore, a simple equilibrium cycle analysis is performed using the supplied fuel composition for the equilibrium cycle given in Table 4.3-3 of Reference [22].

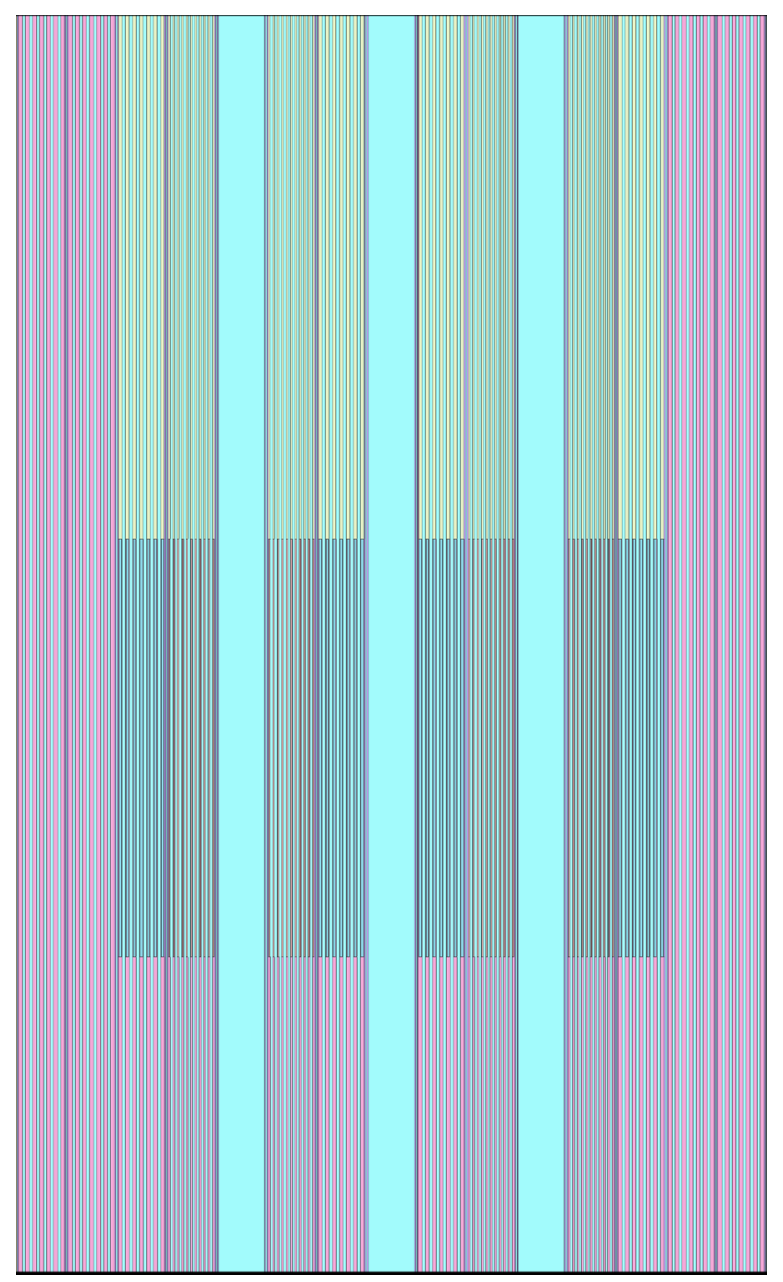

Figure 10. Elevation view (XZ cut) of the Serpent2 model of the PRISM fast reactor design from References [22] and [23]. 


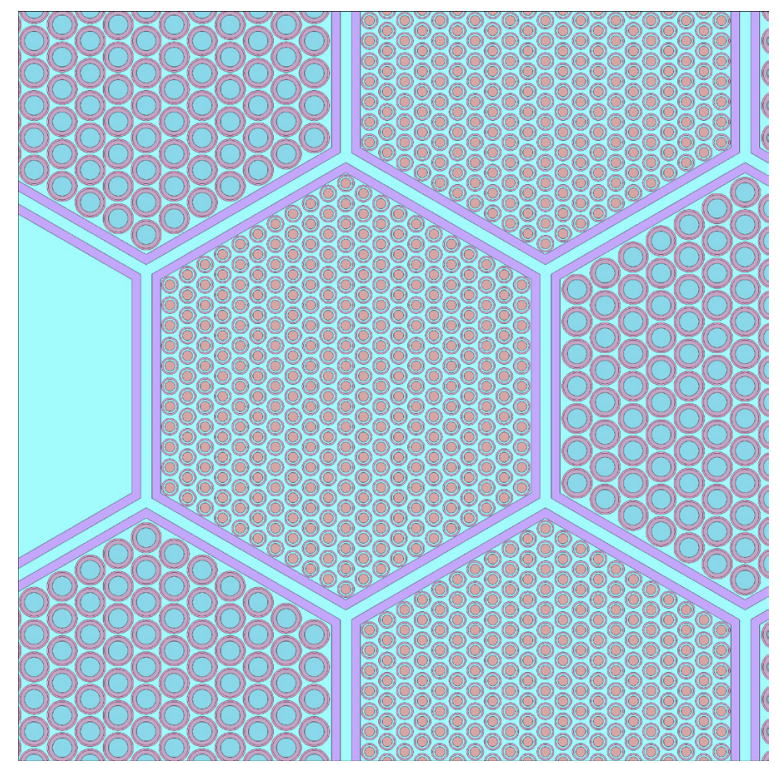

Figure 11. Detailed view of fuel and blanket assemblies in Serpent2 model of the PRISM fast reactor design from References [22] and [23].

The results of the analysis using the supplied fuel compositions are given in Table 5. The peak fast flux for the equilibrium cycle is slightly larger than $2.0 \times 10^{15} \mathrm{n} / \mathrm{cm}^{2}-\mathrm{s}$, while the peak linear power is about $30 \mathrm{~kW} / \mathrm{m}$. The power fraction in the driver fuel assemblies is about $75 \%$ at the beginning of equilibrium cycle and drops to $69 \%$ at the end of the equilibrium cycle. Note that the fuel composition supplied in Reference [22] has a lumped fission product value, which was not modeled in the Serpent2 model. The effect of the lumped fission product on the reactivity can be quantified by replacing it with natural molybdenum. The mass of lumped fission products and their effect on the core reactivity are also given in Table 5. The effect is about 900, 1,000, and 1,600 pcm for the beginning, middle, and end of the equilibrium cycle, respectively.

Table 5. Summary of results of PRISM analysis at different compositions.

\begin{tabular}{|c|c|c|c|}
\hline Parameter & $\begin{array}{c}\text { Beginning of } \\
\text { Equilibrium Cycle }\end{array}$ & $\begin{array}{c}\text { Middle of } \\
\text { Equilibrium Cycle }\end{array}$ & $\begin{array}{c}\text { End of } \\
\text { Equilibrium Cycle }\end{array}$ \\
\hline $\mathrm{k}_{\mathrm{eff}}$ & $1.04498 \pm 0.00014$ & $1.04179 \pm 0.00014$ & $1.04397 \pm 0.00014$ \\
\hline Heavy Metal Mass (ton) & 14.87 & 14.76 & 14.65 \\
\hline Uranium Mass (ton) & 13.32 & 13.19 & 13.06 \\
\hline Plutonium Mass (ton) & 1.55 & 1.56 & 1.58 \\
\hline $\begin{array}{l}\text { Peak Fast Flux }(\mathrm{E}>0.1 \mathrm{MeV}) \\
\left(\mathrm{n} / \mathrm{cm}^{2}-\mathrm{s}\right)\end{array}$ & $2.2 \times 10^{15}$ & $2.2 \times 10^{15}$ & $2.2 \times 10^{15}$ \\
\hline Peak Total Flux (n/ $\mathrm{cm}^{2}$-s) & $3.1 \times 10^{15}$ & $3.2 \times 10^{15}$ & $3.2 \times 10^{15}$ \\
\hline $\begin{array}{l}\text { Driver-Fuel Peak Linear Power } \\
(\mathrm{kW} / \mathrm{m})\end{array}$ & 30 & 29 & 27 \\
\hline Driver-Fuel Power Fraction (\%) & $75 \%$ & $72 \%$ & $69 \%$ \\
\hline $\begin{array}{l}\mathrm{k}_{\text {eff }} \text { with Modeling Fission Products } \\
\text { as Natural Molybdenum }\end{array}$ & $1.03602 \pm 0.00014$ & $1.03211 \pm 0.00014$ & $1.02748 \pm 0.00014$ \\
\hline
\end{tabular}




\subsubsection{PRISM MOD-A Design: Low-Enriched Uranium Core}

The PRISM MOD-A design contains 54 Zone 1 driver-fuel assemblies, 45 Zone 2 driver-fuel assemblies, six control and one secondary shutdown assemblies, and three gas-expansion module assemblies [24]. There are 42 HT9 reflector assemblies surrounding the Zone 2 driver fuel and 102 shield assemblies at the periphery. Figure 12 shows the plan view of the Serpent2 model of the PRISM MOD-A design, whereas Figure 13 shows the elevated view of the Serpent 2 model; note that the control and secondary shutdown assemblies, as well as the gas-expansion modules, are filled with sodium in the model.

The details of the driver-fuel assembly, reflector, and shield assembly designs are taken from the original PRISM design, as described in Table 4, because this information is not given in the PRISM MOD-A report [24]. Low-enriched uranium (LEU) metal fuel in the form of $\mathrm{U}-10 \% \mathrm{Zr}$ is modeled in the driver fuel; however, two different enrichments are assumed in different zones: $19 \%$ enriched in Zone 1 and $10 \%$ enriched in Zone 2. Both fuel types are assumed to have $75 \%$ smear density. The fresh core in the model contains about 6.3 tons of uranium (of which 1.2 tons is ${ }^{235} \mathrm{U}$ ) in Zone 1 and about 5.3 tons of uranium (of which 0.53 tons is ${ }^{235} \mathrm{U}$ ) in Zone 2, respectively.

The calculated $k_{\text {eff }}$ of the fresh core is $1.05973 \pm 0.00004$, and the peak fast flux $(E>0.1 \mathrm{MeV})$ is about $2.5 \times 10^{15} \mathrm{n} / \mathrm{cm}^{2}-\mathrm{s}$, while the peak total flux is $3.5 \times 10^{15} \mathrm{n} / \mathrm{cm}^{2}-\mathrm{s}$. The peak linear power in the core is about $26 \mathrm{~kW} / \mathrm{m}$. The preliminary depletion calculation showed that such a core composition would achieve 15-month cycle length with three-batch loading, leading to an average fuel burnup of about $50 \mathrm{GWd} / \mathrm{t}$ heavy metal (HM). Note that the results presented here are not for an optimized core; they are for a first attempt to analyze the two-zone core of the PRISM MOD-A design.

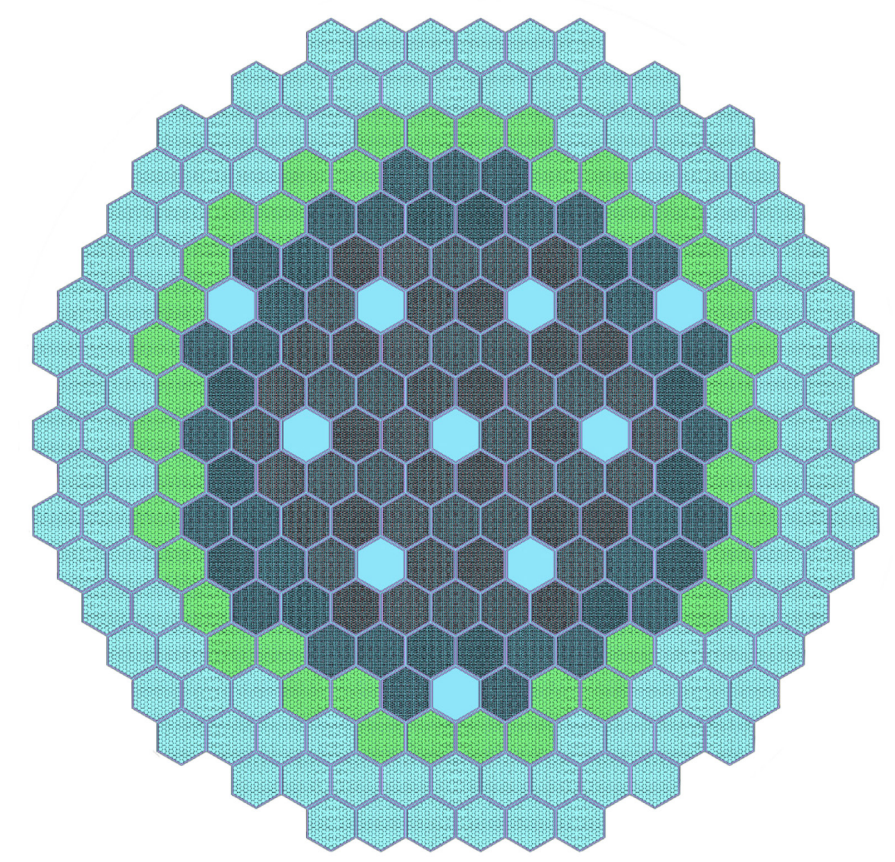

Figure 12. PRISM MOD-A LEU configuration plan view. 


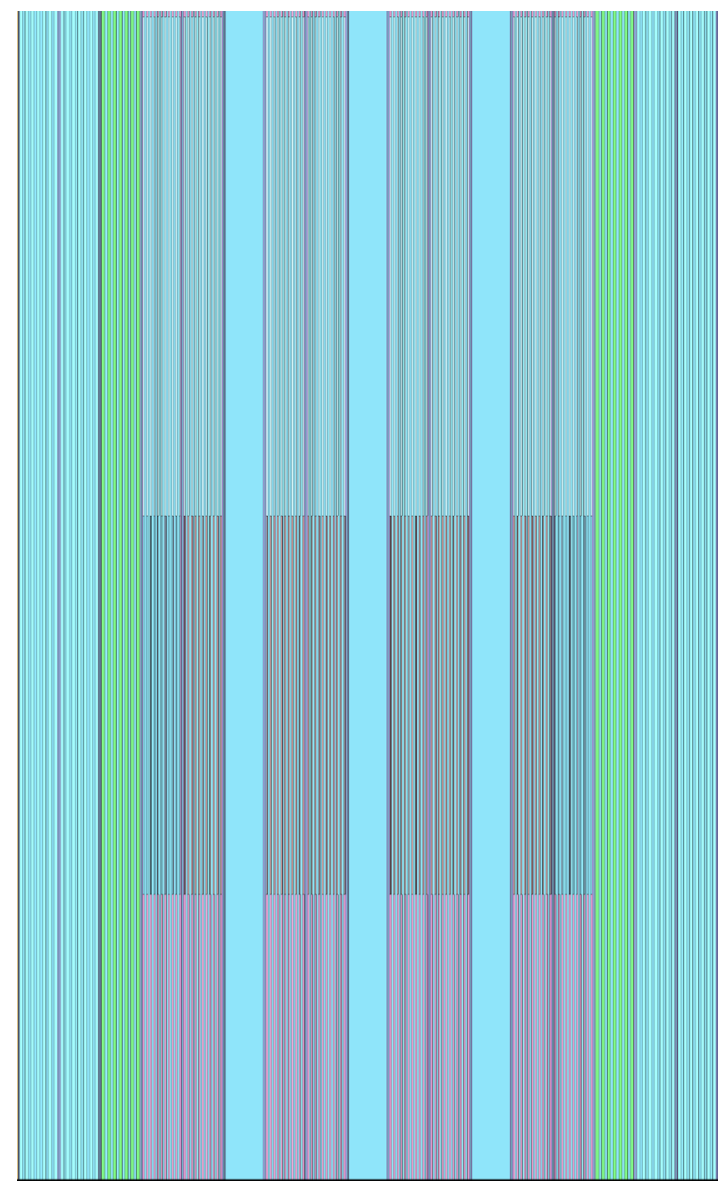

Figure 13. PRISM MOD-A: LEU configuration elevated view.

\section{COUPLED TEST REACTOR CONCEPTS}

The VCTR concept is described in Reference [1]. There, two approaches to the coupling concept are described, with one approach having the main purpose of minimizing the power and fissile inventory and the other approach having the main purpose of minimizing the flux gradients. In the first case, the coupling coefficients, $k_{F T}$ and $k_{T F}$, are maximized by bringing the moderated fuel assemblies as close to the fast zone as possible; the configuration is said to be "boosted." In the second case, the impact on the power and fissile inventory of the fast zone will be less than in the first case, because the objective of the thermal fuel assemblies is to provide additional control of the irradiation conditions in the thermal zone; the coupling coefficients will be smaller than in the first (boosted) case. Reference [1] presents and describes examples of both cases. However, the KNK-II example showed that bringing the moderation of neutrons into the fuel assemblies in the boosted case could increase the reactivity of the core. Thus, the cycle length could be increased or the fuel loading could be reduced.

The fuel assembly, control rod, reflector, etc. of the VCTR core designs presented in this report can be found in Reference [1] unless otherwise noted.

\subsection{Plutonium Core}

The VCTR design in Reference [1] uses LEU for the boosted case, producing $3.5 \times 10^{15} \mathrm{n} / \mathrm{cm}^{2}$-s peak fast flux at the test location at 270-MW power. The LEU inventory in the core is approximately 2.85 tons. Several different designs are considered in Reference [1], including a plutonium core beside the LEU core. The plutonium and LEU content of the plutonium-LEU design (having the same geometry as the 
LEU-only design) is about 1.22 tons (including $177 \mathrm{~kg}$ of plutonium) and 1.63 tons (including $244 \mathrm{~kg}$ of $\left.{ }^{235} \mathrm{U}\right)$, respectively.

The use of plutonium in the driver-fuel assemblies could not only help to increase the peak fast flux, but also help to increase the volume of test locations by providing additional reactivity. Figure 14 shows the plan view of the Serpent 2 model of such a design. It has 30 fuel assemblies in the fast zone fueled with U-Pu-6\%Zr metal alloy with $19.4 \mathrm{wt} \%$ weapons-grade plutonium. The fast zone has three central closed-loop locations and several possible peripheral fast-spectrum closed-loop/test locations. The fast zone is surrounded by 24 stainless-steel reflector assemblies, which separate 18 booster fuel assemblies from the fast zone. The booster fuel assemblies consist of $\mathrm{U}-10 \% \mathrm{Zr}$ with ${ }^{235} \mathrm{U}$ enrichment of $16 \mathrm{wt} \%$. The power peak due to the graphite reflector is overcome by the enrichment zoning ( $3 \mathrm{wt} \%$ and $7 \mathrm{wt} \%$ of $\left.{ }^{235} \mathrm{U}\right)$.

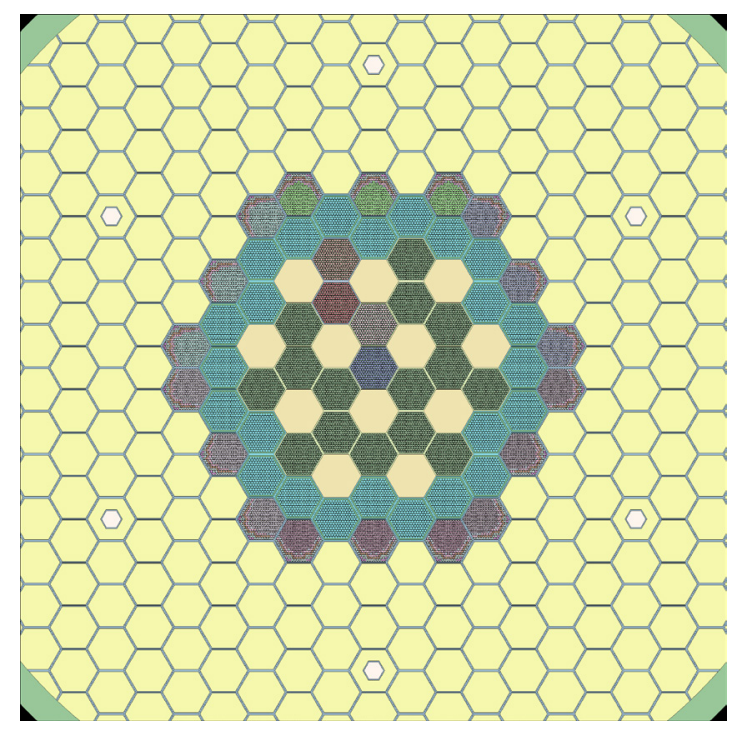

Figure 14. Boosted VCTR concept using plutonium in the fast zone.

The calculated fresh core $\mathrm{k}_{\mathrm{eff}}$ is $1.03769 \pm 0.00004$. The fast and thermal zones are also tightly coupled, as demonstrated by the calculated neutronic parameters: $k_{F}=0.87, k_{T}=0.65, k_{F T}=0.21$, and $k_{T F}=0.32$. The peak fast fluxes $(\mathrm{E}>0.1 \mathrm{MeV})$ at the central and peripheral closed-loop locations are $4.0 \times 10^{15} \mathrm{n} / \mathrm{cm}^{2}$-s and $3.0 \times 10^{15} \mathrm{n} / \mathrm{cm}^{2}$-s, respectively. The peak thermal flux $(\mathrm{E}<0.625 \mathrm{eV})$ is $1.1 \times 10^{15}$ $\mathrm{n} / \mathrm{cm}^{2}$-s. The maximum linear power for the booster-fuel assemblies is $50 \mathrm{~kW} / \mathrm{m}$ and for the fast-zone fuel assemblies is $35 \mathrm{~kW} / \mathrm{m}$.

The use of plutonium in the design shown in Figure 14 not only improves the performance of the core $\left(4.0 \times 10^{15} \mathrm{n} / \mathrm{cm}^{2}\right.$-s versus $3.5 \times 10^{15} \mathrm{n} / \mathrm{cm}^{2}$-s [1] peak fast flux $)$, but also allows increases to the test volumes (three versus one fast-spectrum closed loop). The thermal neutrons from the graphite reflector surrounding the booster-fuel assemblies cause high power peaking in the fuel pins next to the reflector. Therefore, fuel-enrichment zoning is required in this region. The thermal neutrons are captured by the outermost fuel pins; therefore, the inner parts of the booster-fuel assemblies have a fast-neutron spectrum. The purpose of using stainless-steel reflector between the driver- and booster-fuel assemblies is to provide enough space for secondary control (shutdown) systems.

The booster-fuel assemblies provide reactivity for allowing the use of LEU in this region, thus reducing the required plutonium content. If enough plutonium is available for the entire operation of such a test reactor, then the same or better performance could be achieved using only driver-fuel assemblies, i.e., without using booster-assembly or coupled-core concepts. However, then the versatility characteristic will be lost. 


\subsection{LEU Core}

The VCTR-LEU concept described in Reference [1] uses the graphite reflector surrounding the booster-fuel assemblies as the source of neutron moderation. The outer three to four rings of the fuel pins next to the graphite reflector in these booster-fuel assemblies are affected by the thermal neutrons. However, if the neutron moderation is realized within the fuel assemblies by introducing moderator pins $\left(\mathrm{ZrH}_{1.6}\right.$, for example), as in the KNK-II case, the amount of fuel pins that have thermal spectrum would be increased, thus increasing the total reactivity of the system. Figure 15 illustrates such a design, which has 30 fuel assemblies in the fast zone. The fast zone has one central closed-loop location, three peripheral closed-loop/test locations, and three control-rod locations. One ring of stainless-steel reflector acts as thermal neutron filter. The thermal-fuel assemblies are located in $2.5-\mathrm{cm}$-thick, zirconium-alloy, canned graphite. The thermal-fuel assemblies contain a total of 91 pins, of which 31 are moderator pins and 60 are fuel pins. The fast-zone fuel assemblies contain $19.9 \%$ enriched $\mathrm{U}-6 \% \mathrm{Zr}$, while the thermal-zone fuel assemblies contain $12 \%$ enriched $\mathrm{U}-10 \% \mathrm{Zr}$.

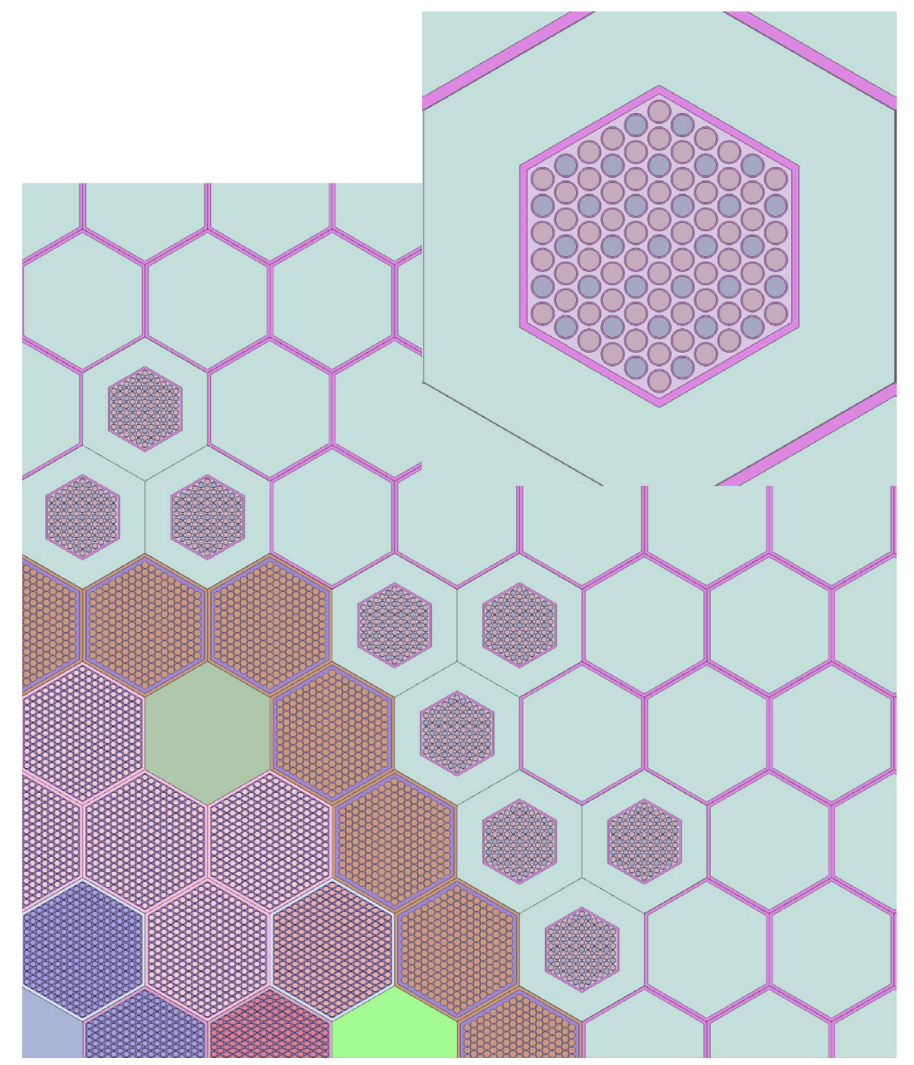

Figure 15. Boosted VCTR-LEU concept using neutron moderation within the booster-fuel assemblies.

The calculated fresh core $\mathrm{k}_{\text {eff }}$ is $1.02978 \pm 0.00004$, which gives about 75 days of cycle length in a three-batch loading scheme. The fast and thermal zones are also tightly coupled, as demonstrated by the calculated neutronic parameters: $k_{F}=0.91, k_{T}=0.65, k_{F T}=0.18$, and $k_{T F}=0.25$. The peak fast flux $(\mathrm{E}>0.1 \mathrm{MeV})$ at the central and peripheral closed-loop locations is $3.5 \times 10^{15} \mathrm{n} / \mathrm{cm}^{2}-\mathrm{s}$ and $2.0 \times 10^{15}$ $\mathrm{n} / \mathrm{cm}^{2}$-s, respectively. The peak thermal flux $(\mathrm{E}<0.625 \mathrm{eV})$ is $0.8 \times 10^{15} \mathrm{n} / \mathrm{cm}^{2}$-s. The maximum linear power for the booster fuel assemblies is $40 \mathrm{~kW} / \mathrm{m}$ and for the fast zone fuel assemblies is $24 \mathrm{~kW} / \mathrm{m}$.

Even though bringing the moderation inside the fuel assembly increases the reactivity, the reactivity swing also increases due to the increased power peaking in these assemblies. If the optimum moderation is used, the linear power peak per fuel pin increases significantly. Therefore, an under-moderated fuel assembly is designed. Also, the number of moderated-fuel assemblies increased compared to the design in 
Reference [1] to lower the power peaking. Even though it is not optimized, the VCTR-LEU design with the moderating booster assemblies, as shown in Figure 15, has a total of $10 \%$ less HM than the LEU design in Reference [1], which corresponds to about $7 \%$ less ${ }^{235} \mathrm{U}$. The use of moderator solid pins might significantly reduce the fuel inventory if optimized further. Note that these designs are not optimized, and the results shown here are preliminary.

\subsection{Parametric Study on LEU Core}

A parametric study has been conducted to assess the minimum power requirement needed for ${ }^{235} \mathrm{U}$ metal-fueled fast-test reactor capable of generating a fast $(>100 \mathrm{keV})$ flux of $4.0 \times 10^{15} \mathrm{n} / \mathrm{cm}^{2}$-s at the test location. The parameter field was related to different forms and enrichments for the fuel. In particular, the following four cases were considered:

1. $\operatorname{UZr}(6)$ with $20 \%$ enrichment; $\operatorname{Zr}(6)$ implies $6 \%$ of zirconium in the $\mathrm{UZr}$ alloy

2. $\operatorname{UZr}(6)$ with $27 \%$ enrichment

3. $\operatorname{UZr}(10)$ with $20 \%$ enrichment and $10 \%$ of zirconium in the alloy

4. $\operatorname{UZr}(10)$ with $27 \%$ enrichment.

The two enrichments correspond to the cases where proliferation limits are imposed (20\%) or not imposed (27\%). Moreover, a set of constraints, besides the one on the fast flux at the test location, was adopted. These constraints include:

- 1 -m core height

- Only one testing assembly at the center of the reactor

- Assembly pitch $(12.245 \mathrm{~cm})$, pin, and wrapper that are the same as those in a VCTR

- Volume fractions that are the same as those in a VCTR

- Fuel smeared density of $75 \%$

- Stainless-steel radial reflectors (bottom and upper reflectors that are the same as those in a VCTR)

- Only one enrichment zone for the core

- Cycle length of 100 days with three-batch core. In order to simplify calculations, this is obtained by using a linear reactivity model, i.e., by imposing a $\mathrm{k}_{\mathrm{eff}}=1$ after 200 days of continuous burnup.

The calculations were performed using ENDF/B-VII.0 cross sections and the ERANOS fast-reactor code system. In the first phase, calculations were run using in $\mathrm{R}-\mathrm{Z}$ geometry, $\mathrm{S}_{4}$ approximations using the BISTRO code. Then the final configurations were run in full HEX-3D geometries and full $\mathrm{P}_{3}$ transport approximation, sixth-order internal spatial expansion, and linear partial current surface dependence using the VARIANT code.

Results are shown in Table 6. Note that it was possible to achieve the desired fast-flux level thanks to a sharp radial gradient in the core region. In fact, Figure 16 shows such a gradient for the fast flux of the configuration of the $\mathrm{UZr}(10)$ with $20 \%$ of ${ }^{235} \mathrm{U}$ enrichment, which is considered the reference (or base) case. It still remains to be seen if such a gradient is acceptable in a fuel-management strategy. Indeed, in view of the fact that it is a test reactor design effort, it is possible to foresee a requirement for the power peak radial factor that is less stringent than those typically in place for power-generating reactors.

Concerning control rod requirements, the six control rods considered provide an ample margin of reactivity worth. In fact, in the most penalizing configuration (i.e., the reference configuration in this parametric study), the total reactivity worth is $24,410 \mathrm{pcm}$. This suggests that three control rods should probably be sufficient and the three remaining positions could be used for extra testing locations. Further 
optimization could be achieved using more effective reflectors (e.g., using nickel instead of stainless steel); however, economic drawbacks need to be evaluated.

Table 6. Power and main characteristics of the test fast reactor configurations.

\begin{tabular}{|c|c|c|c|c|c|c|c|c|c|}
\hline $\begin{array}{l}\text { Fuel } \\
\text { Type }\end{array}$ & $\begin{array}{c}\text { Enrichment } \\
(\%)\end{array}$ & $\begin{array}{l}\text { Power } \\
\text { (MW) }\end{array}$ & $\begin{array}{c}\text { Core } \\
\text { Diameter } \\
(\mathrm{cm})\end{array}$ & $\begin{array}{c}\# \\
\text { Fissile } \\
\text { Assemb. }\end{array}$ & $\begin{array}{c}\# \\
\text { Control } \\
\text { Rods }\end{array}$ & $\begin{array}{c}\text { Max } \\
\text { Power } \\
\text { Density } \\
\text { (W/cc) }\end{array}$ & $\begin{array}{c}\text { Burnup } \\
\text { Swing } \\
\text { (pcm) }\end{array}$ & $\begin{array}{c}\text { Initial } \\
\text { BOC }{ }^{235} \mathrm{U} \\
\text { Mass } \\
(\mathrm{kg})\end{array}$ & $\begin{array}{c}\text { Final EOC } \\
{ }^{235} \text { U Mass } \\
(\mathrm{kg})\end{array}$ \\
\hline $\mathrm{UZr}(6)$ & 20.0 & 346 & 95 & 54 & 6 & 786 & 2,464 & 767 & 692 \\
\hline $\mathrm{UZr}(6)$ & 27.0 & 244 & 78 & 30 & 6 & 939 & 3,200 & 575 & 522 \\
\hline $\mathrm{UZr}(10)$ & 20.0 & 388 & 110 & 66 & 6 & 742 & 2,589 & 852 & 767 \\
\hline UZr(10) & 27.0 & 272 & 85 & 37 & 6 & 878 & 3,273 & 645 & 584 \\
\hline
\end{tabular}

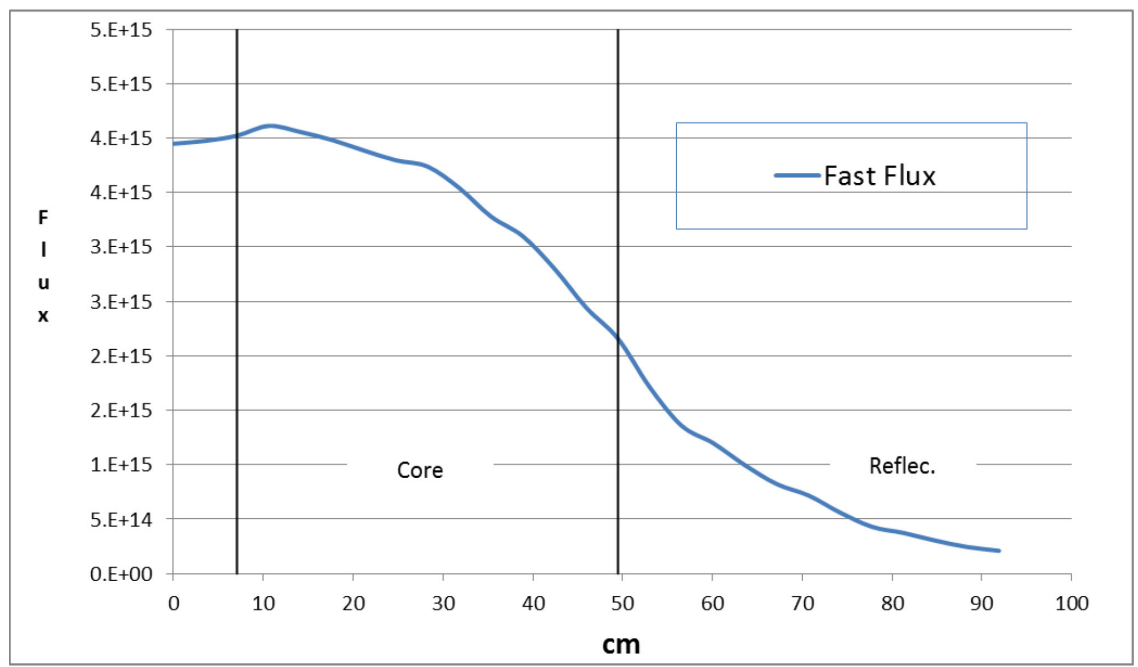

Figure 16. Fast flux radial traverse for the $\operatorname{UZr}(10) 20 \%$ enrichment configuration.

Finally, several attempts to use a booster zone, with no filter region, were made using a moderating material, $\mathrm{ZrH}_{1.6}$, that produces a local epithermal spectrum. Note that not all of the calculations are reported here, but, in summary, two major drawbacks were found to this approach. While the initial reactivity level was substantially increased (several thousands of pcms), the burnup swings also were increased in a more significant way than a corresponding booster-deprived configuration. Moreover, the booster would induce a flattening of the radial flux distribution, negating achievement of the needed level of fast flux, again when compared to a corresponding standard configuration (e.g., having the same amount of fissile material). Note that there are several differences that can explain an apparent inconsistency with the previous LEU "booster" calculations, and in particular:

- There was no filter zone

- Stainless-steel reflector was used instead of graphite reflector

- $10 \%$ enrichment was used in moderated zone

- The fast-flux requirement was $4 \times 10^{15}$ (instead of $3.5 \times 10^{15}$ ), and the cycle length was 100 days (instead of 75). 
The full spectrum of possible variable parameters was not studied, and a more comprehensive investigation is needed to better assess the booster option.

\section{DISPLACEMENTS-PER-ATOM ANALYSIS}

It is important to quantify the radiation damage that a test sample would receive in a test reactor. To evaluate radiation damage, a fundamental parameter that characterizes lattice displacement events is required. DPA, the number of times that an atom is displaced for a given fluence, has been used to compare radiation damage from different radiation sources. It is a damage-based exposure unit and represents the number of atoms displaced from their normal lattice sites as a result of energetic particle bombardment. DPA is a standard measure for computing neutron- and gamma-induced radiation damage of materials that are found in radiation-prone environments. DPA essentially provides the correlation between mechanical structural damage properties associated with the level of radiation that the material has encountered over the time span inside the neutron-radiation environment. A report released by the Organization for Economic Cooperation and Development/Nuclear Energy Agency in 2015 [25] gives a good summary of the theory and the state-of-the-art approaches for the radiation damage in materials. A short description of the theory is provided in this section for completeness of the analysis.

The number of defects produced, $\mathrm{N}_{\mathrm{d}}$, for the available energy for damage production, $\mathrm{T}_{\mathrm{d}}$, can be determined by the modified Kinchin-Pease equation, which is also known as NRT (Norgett, Robinson and Torrens) equation [25], where $\mathrm{E}_{\mathrm{d}}$ is the threshold displacement energy for the element considered:

$N_{d}\left(T_{d}\right)=\left[\begin{array}{c}0, \quad T_{d}<E_{d} \\ 1, \quad E_{d}<T_{d}<2 E_{d} / 0.8 \\ \frac{0.8 T_{d}}{2 E_{d}}, \quad 2 E_{d} / 0.8<T_{d}<\infty\end{array}\right]$

The use of the binary collision approximation factor " 0.8 " includes the possibility of defects recombination. Equation (4) can be used to calculate the number of displaced atoms in any material where $E_{d}$ is known. Then the only unknown, the damage energy, $T_{d}$, needs to be calculated in order to obtain an estimate. The damage energy can be calculated by using the neutron flux and the damage energy production cross section. The damage output of the HEATR module of NJOY code [26] is the damage energy production cross section, $\sigma_{d}$ given in unit of eV-barns. The DPA rate at time $t_{e}$, can be calculated as:

$\mathrm{dpa}=\int_{0}^{t_{e}} \frac{0.8}{2 E_{d}} \phi(t) \sigma_{d}(t) d t$

\subsection{DPA Calculations}

The damage cross section, $\sigma_{\mathrm{d}}$, and the threshold displacement energy, $\mathrm{E}_{\mathrm{d}}$, are isotope dependent, and therefore having different compositions would result in different estimated DPAs. In order to consistently assess of the DPA achieved in different core concepts, the estimate needs to be performed for the same material, using the same assumptions. The DPA assessment described in this report is based on using a ${ }^{56} \mathrm{Fe}$ isotope, unless otherwise indicated.

The damage cross sections generated from NJOY are available in the default MCNP6 cross-section libraries for default temperature values. However, the procedure for generating new cross sections for the Serpent 2 code at different temperatures was investigated and tested. The procedure for generating both damage and gas production cross sections is presented in Appendix A.

The DPA for a 0.5 -cm-radius cylinder located at the center of the central fast-spectrum test loop made of both ${ }^{56} \mathrm{Fe}$ and stainless steel (the composition is given in Table 7) is estimated for the reference LEU VCTR design in Reference [1]. The average total flux at the test location is $3.6 \times 10^{15} \mathrm{n} / \mathrm{cm}^{2}-\mathrm{s}$. For calculating the damage cross section directly from Serpent2 (1) a detector is located in the test location tallying the total flux in the test material, and (2) a detector tallying the damage reaction rate, i.e., 
$\phi(t) \sigma_{d}(t)$, divided by total flux for each isotope in the test material is also located in the test location. The damage cross section for each isotope is then the result of the detector in the Serpent2 output.

Table 7. Stainless-steel composition and the individual DPA data for the solid cylinder located at the center of the fast-spectrum test loop.

\begin{tabular}{|c|c|c|c|c|c|c|c|}
\hline Isotope & $\begin{array}{c}\text { Abundance } \\
(\%)\end{array}$ & $\begin{array}{c}\mathrm{E}_{\mathrm{d}} \\
(\mathrm{eV})\end{array}$ & $\begin{array}{c}\text { Damage Cross } \\
\text { Section } \\
\text { (eV-barns) }\end{array}$ & $\begin{array}{c}\text { DPA/ } \\
\text { second }\end{array}$ & $\begin{array}{c}\text { Weighted } \\
\text { DPA/ } \\
\text { second }\end{array}$ & $\begin{array}{c}\text { DPA at } \\
\text { 300 days }\end{array}$ & $\begin{array}{c}\text { Weighted DPA at } \\
300 \text { days }\end{array}$ \\
\hline${ }^{54} \mathrm{Fe}$ & 4.99 & 40 & $34,458.92$ & $1.24 \mathrm{E}-06$ & $6.20 \mathrm{E}-08$ & 32.20 & 1.61 \\
\hline${ }^{56} \mathrm{Fe}$ & 78.6 & 40 & $26,403.43$ & $9.52 \mathrm{E}-07$ & $7.48 \mathrm{E}-07$ & 24.67 & 19.39 \\
\hline${ }^{57} \mathrm{Fe}$ & 1.81 & 40 & $34,124.14$ & $1.23 \mathrm{E}-06$ & $2.23 \mathrm{E}-08$ & 31.88 & 0.58 \\
\hline${ }^{58} \mathrm{Fe}$ & 0.24 & 40 & $35,087.65$ & $1.26 \mathrm{E}-06$ & $3.04 \mathrm{E}-09$ & 32.78 & 0.08 \\
\hline${ }^{50} \mathrm{Cr}$ & 0.55 & 40 & $34,675.83$ & $1.25 \mathrm{E}-06$ & $6.92 \mathrm{E}-09$ & 32.40 & 0.18 \\
\hline${ }^{52} \mathrm{Cr}$ & 10.66 & 40 & $29,754.86$ & $1.07 \mathrm{E}-06$ & $1.14 \mathrm{E}-07$ & 27.80 & 2.96 \\
\hline${ }^{53} \mathrm{Cr}$ & 1.21 & 40 & $38,385.57$ & $1.38 \mathrm{E}-06$ & $1.67 \mathrm{E}-08$ & 35.86 & 0.43 \\
\hline${ }^{54} \mathrm{Cr}$ & 0.30 & 40 & $28,998.55$ & $1.05 \mathrm{E}-06$ & $3.14 \mathrm{E}-09$ & 27.09 & 0.08 \\
\hline${ }^{58} \mathrm{Ni}$ & 0.36 & 40 & $37,240.78$ & $1.34 \mathrm{E}-06$ & $4.81 \mathrm{E}-09$ & 34.80 & 0.12 \\
\hline${ }^{60} \mathrm{Ni}$ & 0.14 & 40 & $31,817.46$ & $1.15 \mathrm{E}-06$ & $1.59 \mathrm{E}-09$ & 29.73 & 0.04 \\
\hline${ }^{61} \mathrm{Ni}$ & 0.01 & 40 & $34,235.26$ & $1.23 \mathrm{E}-06$ & $7.42 \mathrm{E}-11$ & 31.99 & 0.00 \\
\hline${ }^{62} \mathrm{Ni}$ & 0.02 & 40 & $35,252.96$ & $1.27 \mathrm{E}-06$ & $2.43 \mathrm{E}-10$ & 32.94 & 0.01 \\
\hline${ }^{92} \mathrm{Mo}$ & 0.08 & 60 & $37,859.98$ & $8.58 \mathrm{E}-07$ & $6.70 \mathrm{E}-10$ & 22.25 & 0.02 \\
\hline${ }^{94} \mathrm{Mo}$ & 0.05 & 60 & $35,718.40$ & $8.28 \mathrm{E}-07$ & $4.04 \mathrm{E}-10$ & 21.46 & 0.01 \\
\hline${ }^{95} \mathrm{Mo}$ & 0.08 & 60 & $34,457.93$ & $7.87 \mathrm{E}-07$ & $6.60 \mathrm{E}-10$ & 20.41 & 0.02 \\
\hline${ }^{96} \mathrm{Mo}$ & 0.09 & 60 & $32,760.39$ & $8.10 \mathrm{E}-07$ & $7.09 \mathrm{E}-10$ & 20.99 & 0.02 \\
\hline${ }^{97} \mathrm{Mo}$ & 0.05 & 60 & $33,696.81$ & $7.85 \mathrm{E}-07$ & $3.95 \mathrm{E}-10$ & 20.35 & 0.01 \\
\hline${ }^{98} \mathrm{Mo}$ & 0.13 & 60 & $32,671.48$ & $7.90 \mathrm{E}-07$ & $1.01 \mathrm{E}-09$ & 20.48 & 0.03 \\
\hline${ }^{100} \mathrm{Mo}$ & 0.05 & 60 & $32,884.22$ & $7.50 \mathrm{E}-07$ & $3.80 \mathrm{E}-10$ & 19.43 & 0.01 \\
\hline${ }^{55} \mathrm{Mn}$ & 0.56 & 40 & $31,198.20$ & $1.20 \mathrm{E}-06$ & $6.75 \mathrm{E}-09$ & 31.00 & 0.17 \\
\hline${ }^{7} \mathrm{Total}$ & 100.00 & - & - & - & $9.94 \mathrm{E}-07$ & - & 25.78 \\
\hline
\end{tabular}

The DPA achieved in a year with $80 \%$ availability factor, i.e., 300 days of total irradiation time, is 25.28 for natural iron and 25.78 for the stainless steel, as shown in Table 7. The threshold displacement energy, $E_{d}$, values of each isotope is taken from the NJOY manual [26]. The evaluated damage cross section in eV-barns is also given in Table 7. The use of natural iron for estimating the DPA in different reactor concepts is a good approximation and will give consistent results: about $85 \%$ of the total DPA in the stainless steel sample is due to iron isotopes as shown in Table 7.

The relative contributions of the individual iron isotopes to the DPA of stainless steel solid cylinder located at the center of the fast-spectrum test loop as a function of neutron energy is shown in Figure 18. The contribution of ${ }^{54} \mathrm{Fe}$ to the stainless steel DPA cross section seems to be about $8 \%$ above $100 \mathrm{keV}$ despite the abundance ratio being about $5 \%$. Note that the high contributions of ${ }^{54} \mathrm{Fe}$ are around $10-50$ $\mathrm{keV}$. The main reason for these contribution ratios is the fact that ${ }^{54} \mathrm{Fe}$ has a high (n,p) cross section with a low threshold $(\sim 1 \mathrm{MeV})$ and a high $(\mathrm{n}, \alpha)$ cross section, which is responsible for He production, much higher than that of ${ }^{56} \mathrm{Fe}$. The microscopic damage cross section of ${ }^{54} \mathrm{Fe},{ }^{56} \mathrm{Fe},{ }^{57} \mathrm{Fe}$, and ${ }^{58} \mathrm{Fe}$ as a function of energy, as obtained from the Serpent 2 detector for the fast-spectrum test location, is shown in Figure 18. Note that the damage cross section in Figure 18 is given in units of barns and it is $\frac{0.8}{2 E_{d}} \sigma_{d}$. Since the damage cross section has a steep behavior in energy, as shown in Figure 18 for iron isotopes, with the highest values above about $100 \mathrm{keV}$, it is reasonable for an isotope of an element to have, e.g. in the case of ${ }^{54} \mathrm{Fe}$, higher DPA cross section, which is also the case in Table 7. 


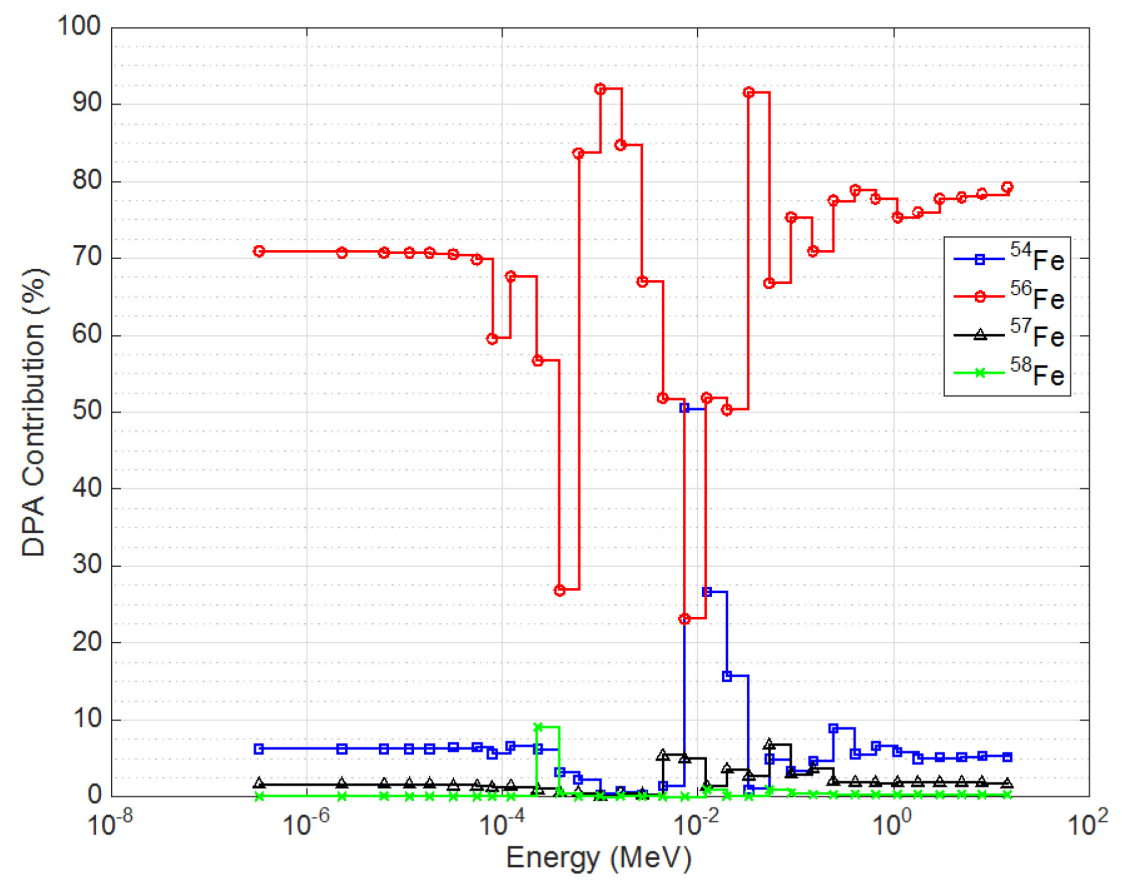

Figure 17. Relative contributions of the individual iron isotopes to the DPA of stainless steel sample in VCTR.

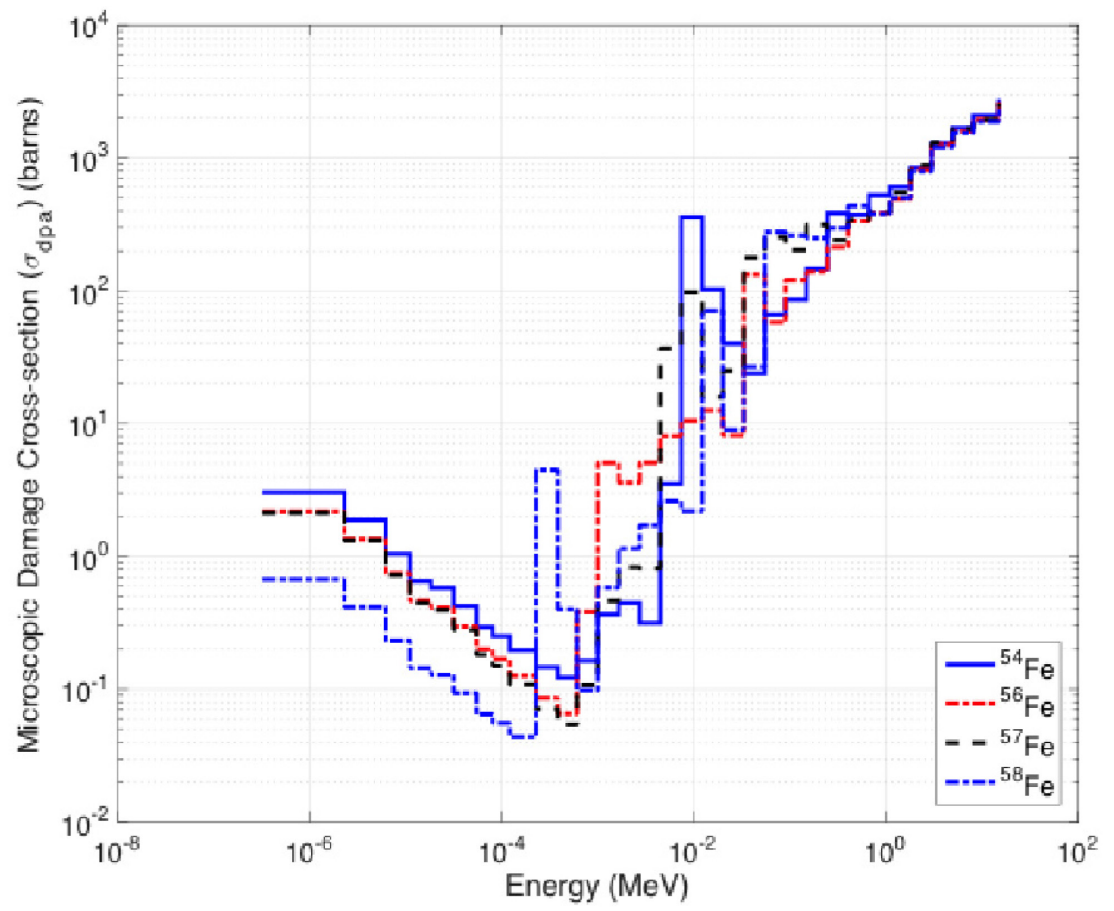

Figure 18. The microscopic damage cross section for different iron isotopes.

\subsubsection{Effect of Different Spectra}

The neutrons with higher energies are more significant in terms of the DPAs accumulated in a test subject. The damage cross section at higher neutron energies $(\mathrm{E}>1 \mathrm{keV})$ is 2 to 3 orders of magnitude 
larger than the damage cross section at lower energies. To assess the effect of the different neutron spectra on the accumulated DPA on a test sample, a simple calculation is performed with super cells (two rings of assemblies) of different core concepts: a typical modular high-temperature gas-cooled reactor (MHTGR), light-water reactor (LWR), sodium-cooled fast reactor (SFR), and VCTR. The super cells for this analysis are shown in Figure 19. A ${ }^{56} \mathrm{Fe}$ sample of $0.1 \mathrm{~cm}$ radius is located at the center of the central assembly.

The neutron spectra in the analyzed core concepts are shown in Figure 20. The main contribution to the accumulated DPA in a test material is due to fast neutrons, as explained in the Subsection 4.1. In a typical LWR spectrum, the neutron flux above $1 \mathrm{MeV}$ accounts for about 40 to $50 \%$ of the neutron flux above $0.1 \mathrm{MeV}$, whereas it accounts for about 15 to $20 \%$ in a typical fast-reactor spectrum. The fast neutron peak is at about $1 \mathrm{MeV}$ and $0.1 \mathrm{MeV}$ in a typical LWR and SFR, respectively. The accumulated DPA in a full-power year in the different core concepts is given in Table 8. The total DPA per year in typical fast-reactor concepts is about 10 times larger than the DPA accumulated in a typical LWR concept, while the total DPA is about 60 times larger than it is in a typical MHTGR.

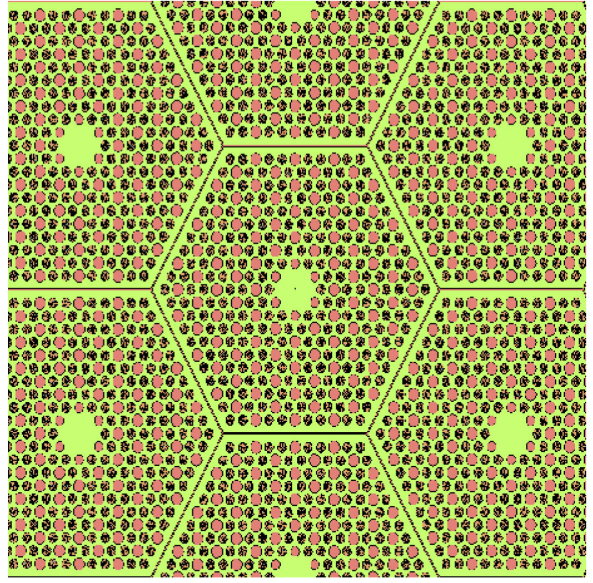

(a)

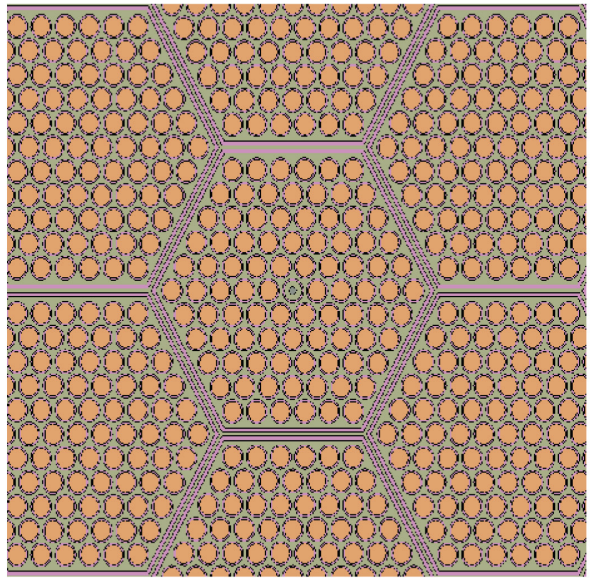

(c)

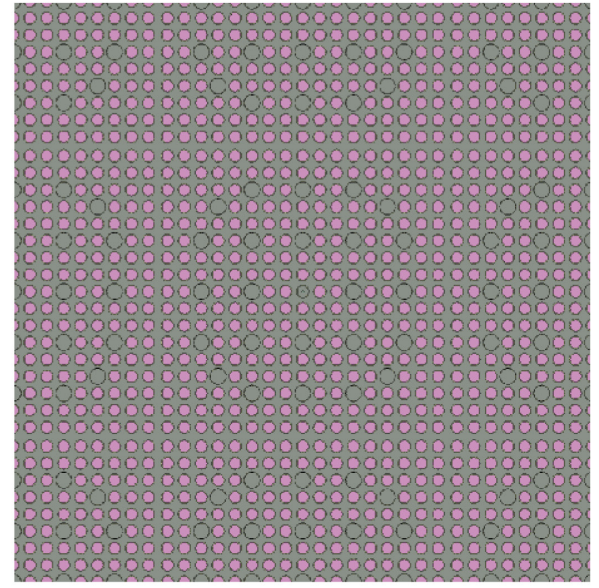

(b)

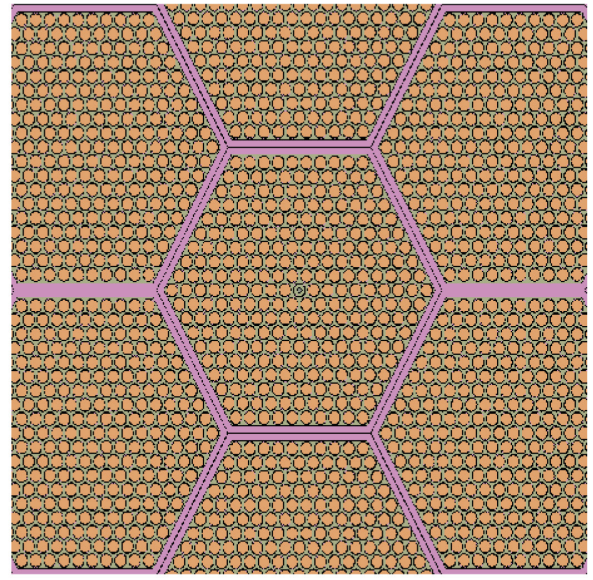

(d)

Figure 19. Super cells used in the DPA analysis for different spectrums: (a) MHTGR, (b) LWR, (c) SFR, and (d) VCTR. All have 0.1-cm-radius solid cylinders made of ${ }^{56} \mathrm{Fe}$ at the center. 


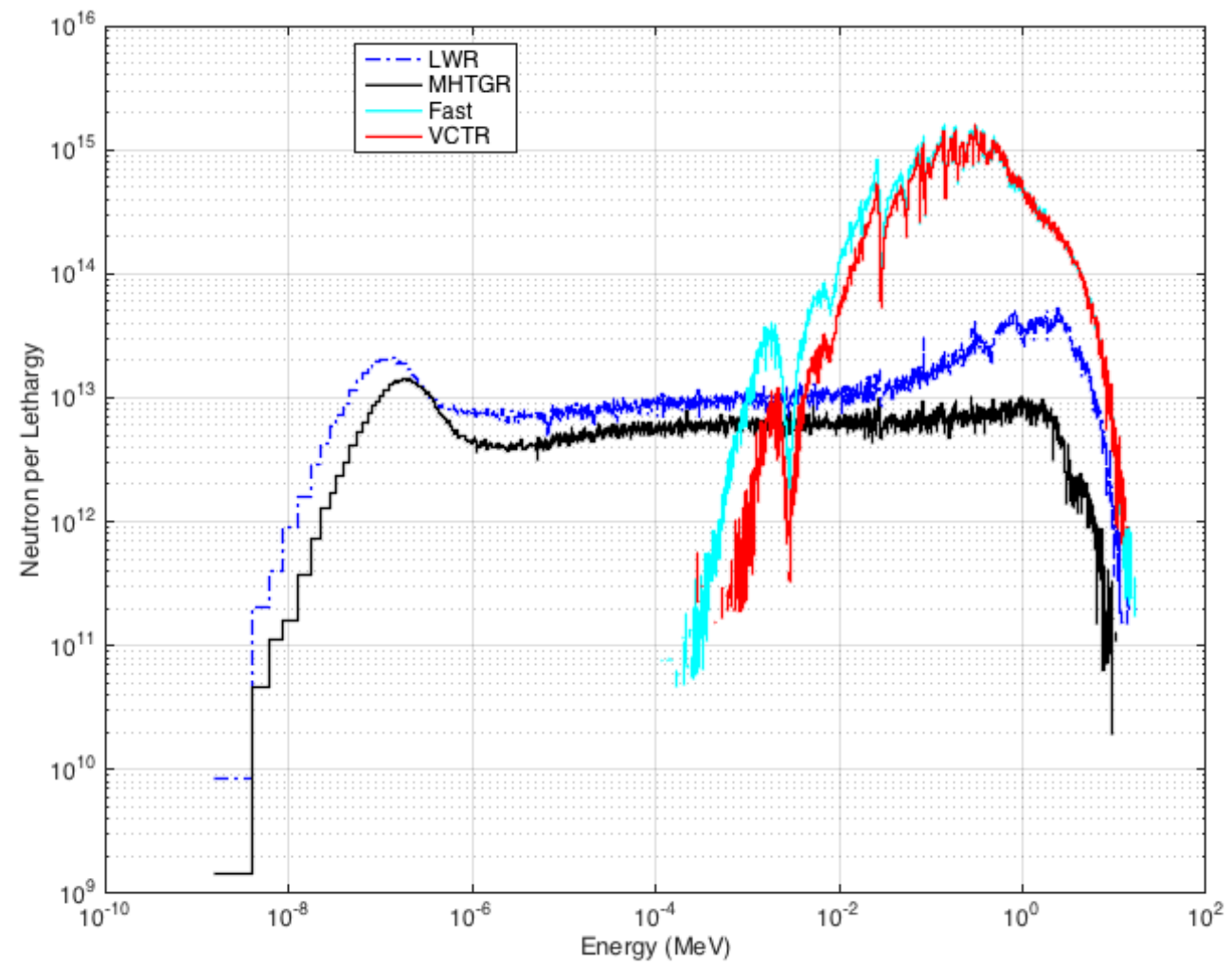

Figure 20. Spectra for the ${ }^{56} \mathrm{Fe}$ sample in unit cells.

Even though the accumulated DPA is typically reported for the total neutron spectrum, Table 8 also presents the accumulated DPA resulting from neutrons above certain energies to identify the importance of the spectrum. The DPA caused by neutrons with energies above $1 \mathrm{MeV}$ is about $40 \%$ of the total DPA for the fast spectrum concepts, while it is about $75 \%$ for LWR and 55\% for MHTGR concepts. The DPA caused by neutrons with energies above $0.1 \mathrm{MeV}$ is above $90 \%$ for all the concepts; however, it is about 97\% for LWR and 90\% for MHTGR concepts.

Table 8. DPA results for a solid cylinder of ${ }^{56} \mathrm{Fe}(\mathrm{r}=0.1 \mathrm{~cm})$ at the center of the unit cells.

\begin{tabular}{|l|r|r|r|r|}
\hline \multicolumn{1}{|c|}{ Parameter } & \multicolumn{1}{c|}{ MHTGR } & \multicolumn{1}{c|}{ LWR } & \multicolumn{1}{c|}{ SFR } & \multicolumn{1}{c|}{ VCTR } \\
\hline Linear Power $(\mathrm{kW} / \mathrm{m})$ & $3.11^{\mathrm{a}}$ & 20 & 20 & 24 \\
\hline Total Neutron Flux $\left(\mathrm{n} / \mathrm{cm}^{2}-\mathrm{s}\right)$ & $1.22 \mathrm{E}+14$ & $2.87 \mathrm{E}+14$ & $3.81 \mathrm{E}+15$ & $3.44 \mathrm{E}+15$ \\
\hline Total DPA (full-power year) & 0.44 & 2.69 & 28.65 & 28.71 \\
\hline DPA (full-power year) $(\mathrm{E}>1 \mathrm{MeV})$ & 0.25 & 2.01 & 11.43 & 11.44 \\
\hline DPA (full-power year) $(\mathrm{E}>0.1 \mathrm{MeV})$ & 0.40 & 2.61 & 26.57 & 26.97 \\
\hline
\end{tabular}

\section{INL ASSESSMENT OF FASTER DESIGN}

ANL developed a fast test reactor concept, FASTER, as a part of the ATDR study under the Advanced Reactor Technologies (ART) program during 2015 and 2016 [27]. FASTER is a passively safe, sodium-cooled, fast-spectrum test reactor that relies on proven technologies. The main desired features of the FASTER concept are a very high fast flux to complement current testing capabilities, many test locations, large test volumes, and high thermal flux. FASTER produces $300 \mathrm{MW}$ of thermal power and 
$120 \mathrm{MWe}$ of electrical power using a superheated steam power conversion system that provides electricity to a local grid [27].

\subsection{Assessment}

The data that are used in the assessment of the FASTER design are taken from Reference [27]. The FASTER concept uses ternary metallic fuel, U-Pu-Zr, with HT9 stainless steel for cladding and structural material. The plutonium content of the fuel is $19.41 \mathrm{wt} \%$, the zirconium content is $6 \mathrm{wt} \%$, and the fuel smear density is $85 \%$. The FASTER concept calls for a design that has very large leakage, has large neutron flux in test locations outside of the active core region, and can thermalize the leaking neutrons to have test locations in thermal spectrum.

Some assumptions needed to be made for the data not present in Reference [27], such as the plutonium vector used in the fuel. Table 9 shows the assumed plutonium vector in the model.

Table 9. Plutonium vector assumed in the Serpent 2 model.

\begin{tabular}{|r|r|}
\hline \multicolumn{1}{|c|}{ Isotope } & \multicolumn{1}{|c|}{ Abundance (\%) } \\
\hline $\mathrm{Pu}-239$ & 87.83 \\
\hline $\mathrm{Pu}-240$ & 11.66 \\
\hline $\mathrm{Pu}-241$ & 0.51 \\
\hline
\end{tabular}

HT9 is assumed to be Fe-12Cr-1Mo-0.5W-0.5Ni-0.25V-0.2C steel, with $7.782 \mathrm{~g} / \mathrm{cm}^{3}$.

The upper and the radial shield assemblies are assumed to contain B4C.

The moderating assemblies used for the neutron thermalization contain beryllium ( $60 \mathrm{vol} \%)$ canned in Zircaloy-2. The volume fraction of the Zircaloy-2 (excluding the can) and the sodium coolant (excluding the sodium between the assemblies) in these assemblies is assumed to be 10 and $15 \mathrm{vol} \%$, respectively.

The full core calculation is performed with Serpent2 code [10]. A fully heterogeneous model of the FASTER core is generated using the assembly details found in Table 5 of Reference [27]. Figure 21 shows the plan view of the Serpent 2 model, and Figure 22 shows the elevation view of the model. The model generation showed that the data given in different parts of Reference [27] are inconsistent, i.e., some data are given for cold core conditions (Table 5 in Reference [27]) while other data are given for the hot core conditions (volume fractions in Subsection 3.1 and HM mass in Table 6 in Reference [27]) without making the distinction.

Note that the results presented in this assessment are for the fresh core and not for the equilibrium core. Preliminary depletion analysis showed that the FASTER design has a cycle length of about 100 days if three-batch loading scheme is assumed. Although no thermal fluid feedback is applied, the preliminary depletion results also showed that the power peaking does not change significantly over the burnup cycle.

No reactivity coefficients or shutdown margin calculations were performed, because the assumptions and the starting conditions for the calculations are not presented in Reference [27]. 


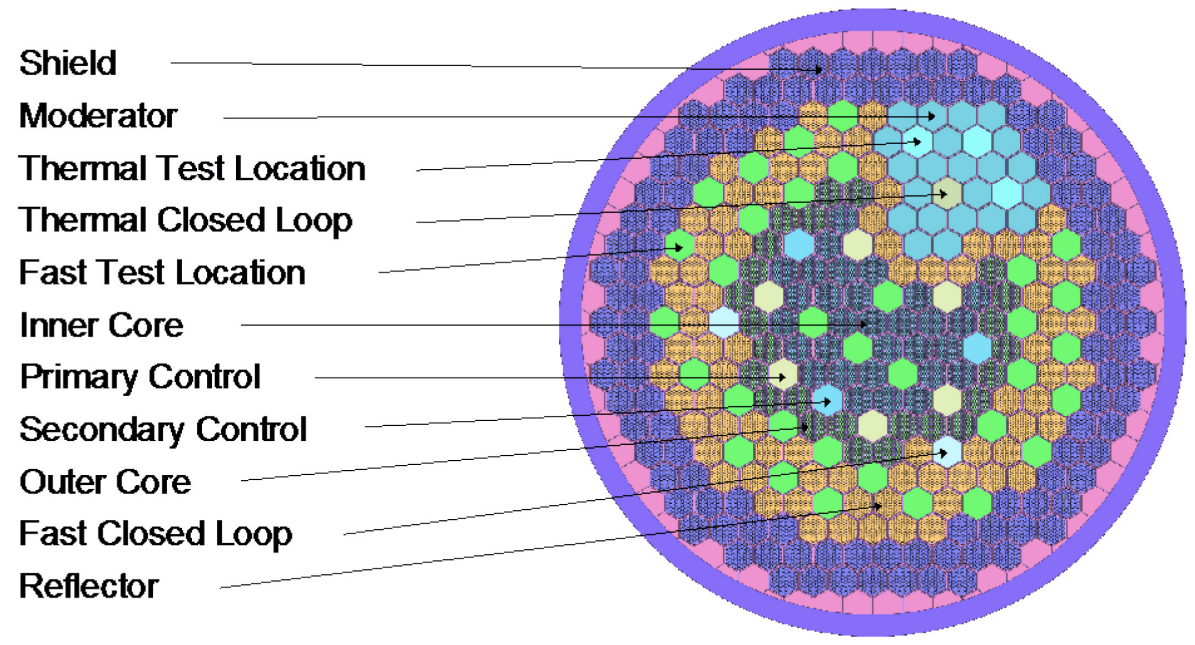

Figure 21. Plan view of the Serpent 2 model of the FASTER design.

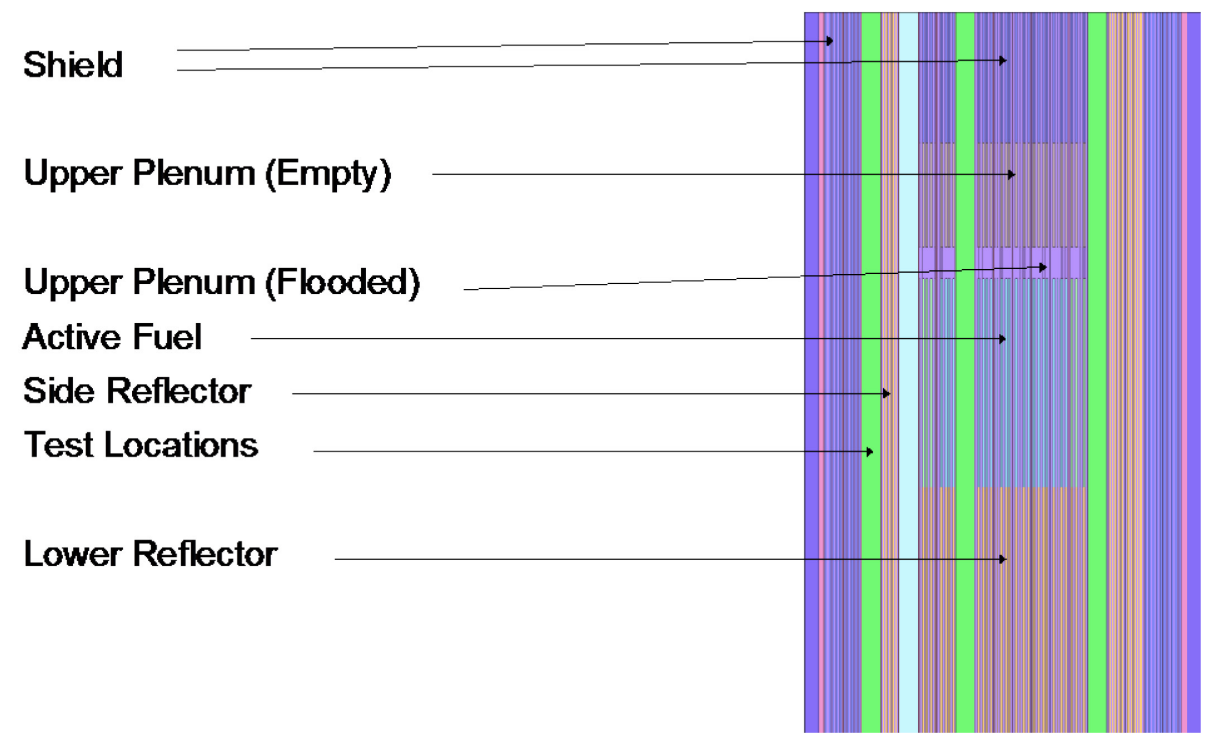

Figure 22. Elevation view of the Serpent2 model of the FASTER design.

The detector locations for tallying the results in Serpent2 model are shown in Figure 23. The fast $(\mathrm{E}>0.1 \mathrm{MeV})$ and thermal $(\mathrm{E}<0.625 \mathrm{eV})$ flux, reaction rates, fission energy deposition, and neutron spectra are tallied in the numbered assemblies. The assembly power peaking factors (pin-by-pin) are tallied in the lettered locations. The radial average three-group fluxes are tallied over the 30-degree slices shown as $\varphi_{1}, \varphi_{2}$, and $\varphi_{3}$. The mesh detector capability in Serpent 2 is also used to produce fast $(\mathrm{E}>0.1 \mathrm{MeV})$ and thermal $(\mathrm{E}<0.625 \mathrm{eV})$ flux profiles over $1-\times 1-\mathrm{cm}$ meshes. 


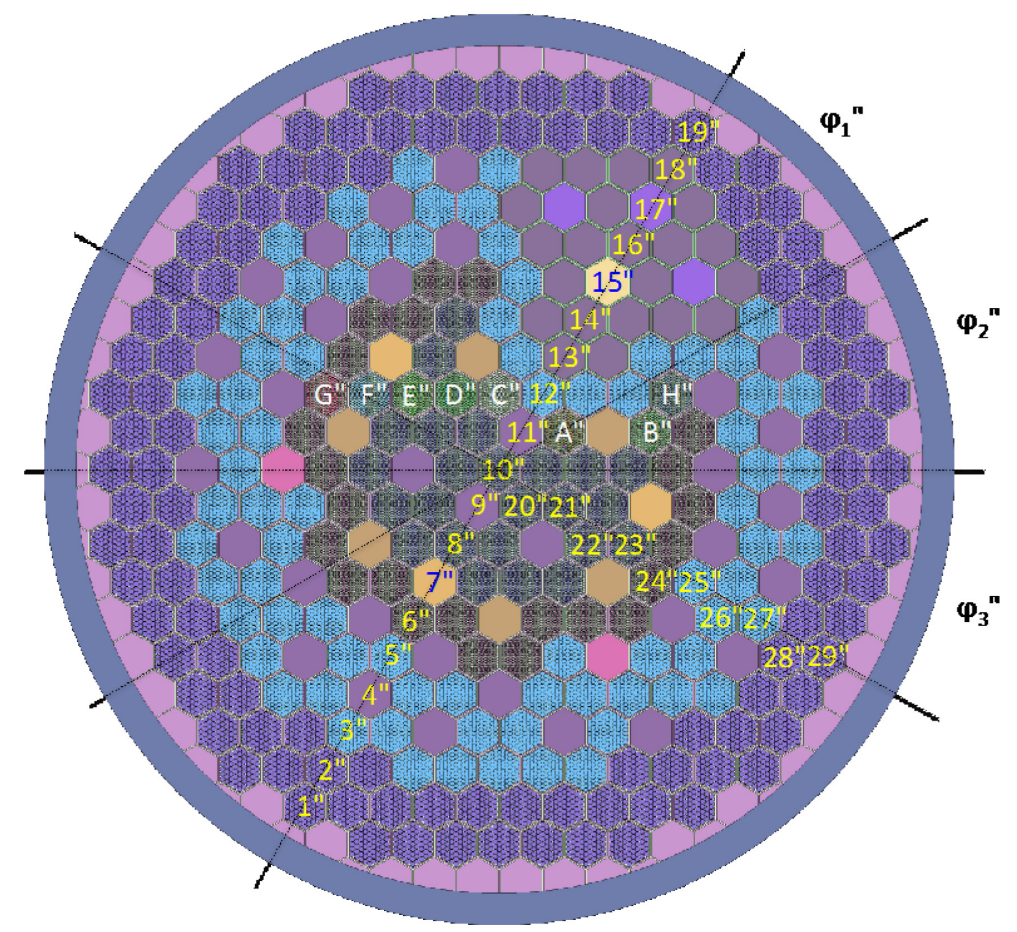

Figure 23. Plan view of the Serpent2 model of the FASTER design showing the tally positions.

The main results for the neutronic analysis of the FASTER design are given in Table 10. Note that these results are for fresh core and not for the equilibrium core. The fresh core multiplication factor is calculated to be $\sim 1.04$; preliminary depletion analysis showed that, using a linear reactivity model, this excess reactivity would be sufficient for a three-batch cycle with a cycle length of about 100 days.

The FASTER core power profile is peaked at the center of the core, due to the high neutron leakage, with a peaking factor of 1.44 , which actually provides very high fast fluxes at the center of the core. The maximum fast flux level is about $5.0 \times 10^{15} \mathrm{n} / \mathrm{cm}^{2}$-s at the center of the core (i.e., Location 10 shown in Figure 23). The larger neutron leakage also provides larger neutron flux in the test location outside the active core as well as a possibility to thermalize the leaking neutrons to provide thermal-spectrum irradiation capability.

The thermalization is achieved via Zircaloy-2 canned beryllium moderator assemblies. No detailed specification for these moderator assemblies is given in Reference [27]; however, Reference [28] states that the beryllium content in these assemblies is $60 \mathrm{vol} \%$. Therefore, $60 \%$ volume fraction is assumed for the beryllium in the moderating assemblies. The calculated maximum thermal flux is about $8.1 \times 10^{14}$ $\mathrm{n} / \mathrm{cm}^{2}-\mathrm{s}$ in this case, which occurs at Location 14 shown in Figure 23 . This value is about $40 \%$ lower than what was reported by ANL $\left(>1.5 \times 10^{15} \mathrm{n} / \mathrm{cm}^{2}-\mathrm{s}\right)$ in Reference [28]. Another calculation is performed assuming the beryllium volume fraction is $100 \%$ in the moderating assemblies, in which case the maximum thermal flux is $1.3 \times 10^{15} \mathrm{n} / \mathrm{cm}^{2}$-s - again, at Location 14 shown in Figure 23 .

The thermalized neutrons can diffuse back to the active core, causing power peaking in the outer regions. Thermal neutrons diffusing back to fast-test locations close to the thermalization zone can affect the neutron spectrum, causing the thermal tail to increase. One row of HT9 reflector is used to filter out any thermal neutrons going back to the active core. The neutron spectra in different locations are shown in Figure 24. Locations 9 and 10 have typical pure fast-neutron spectra, while the effect of diffusing thermal neutrons on the thermal tail can be seen in the fast-test location next to reflector, i.e., Location 11. The increase in the thermal tail in this location is about 2 orders of magnitude. The thermal-spectrum 
closed loop, Location 15, has a typical thermal spectrum without any peak at the neutron peak, because no fission source was in this location and a good thermalization was achieved. The thermalization of the fast neutrons can be seen if the spectra in Location 13 and 15 are compared.

Table 10. Main neutronic parameters for FASTER design calculated with Serpent2.

\begin{tabular}{|l|r|}
\hline \multicolumn{1}{|c|}{ Parameter } & \multicolumn{1}{|c|}{ Value } \\
\hline Fresh Core $k_{\text {eff }}$ & $1.04294 \pm 4.5 \mathrm{E}-05$ \\
\hline Maximum Fast Flux $(\mathrm{E}>0.1 \mathrm{MeV})\left(\mathrm{n} / \mathrm{cm}^{2}-\mathrm{s}\right)$ & $4.94 \times 10^{15}$ \\
\hline $\begin{array}{l}\text { Maximum Thermal Flux }(\mathrm{E}<0.625 \mathrm{eV}) \\
\left(60 \% \text { volume fraction in Be moderator }\left(\mathrm{n} / \mathrm{cm}^{2}-\mathrm{s}\right)\right.\end{array}$ & $8.16 \times 10^{14}$ \\
\hline $\begin{array}{l}\text { Maximum Thermal Flux }(\mathrm{E}<0.625 \mathrm{eV}) \\
(100 \% \text { volume fraction in Be moderator })\left(\mathrm{n} / \mathrm{cm}^{2}-\mathrm{s}\right)\end{array}$ & $1.32 \times 10^{15}$ \\
\hline Cycle Length (days) & 100 \\
\hline Maximum Assembly Averaged Power Density $\left(\mathrm{W} / \mathrm{cm}^{3}\right)$ & 806 \\
\hline Maximum Assembly Averaged Linear Power $(\mathrm{kW} / \mathrm{m})$ & 36 \\
\hline Maximum Power Peaking Factor in the Core & 1.44 \\
\hline
\end{tabular}

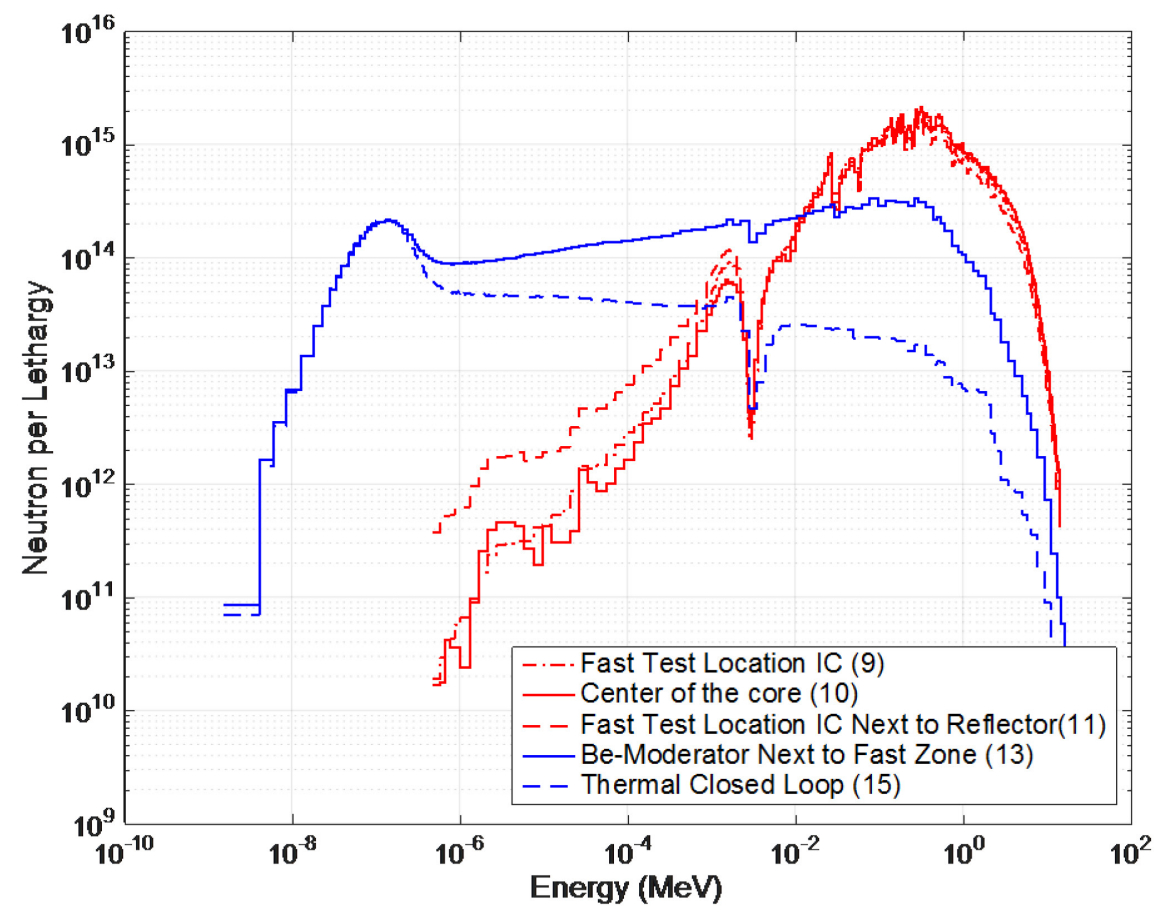

Figure 24. Neutron spectra in different locations shown in Figure 23.

The thermal and fast neutron flux map tallied over a $1-\times 1-\mathrm{cm}$ mesh over the calculation model is shown in Figure 25. The maximum fast flux $\left(\sim 5.0 \times 10^{15} \mathrm{n} / \mathrm{cm}^{2}-\mathrm{s}\right)$ occurs at the border of the center fuel assembly, Location 10, and the center fast-spectrum test location, Location 9. The dips in the neutron flux map in the test locations are due to the presence of sodium in these locations, which is more pronounced in the center of the core. The peak at the thermal flux $\left(\sim 0.8 \times 10^{15} \mathrm{n} / \mathrm{cm}^{2}-\mathrm{s}\right)$ occurs at the border of the first and second moderating assemblies (Locations 13 and 14) next to the thermal-spectrum closed loop. 


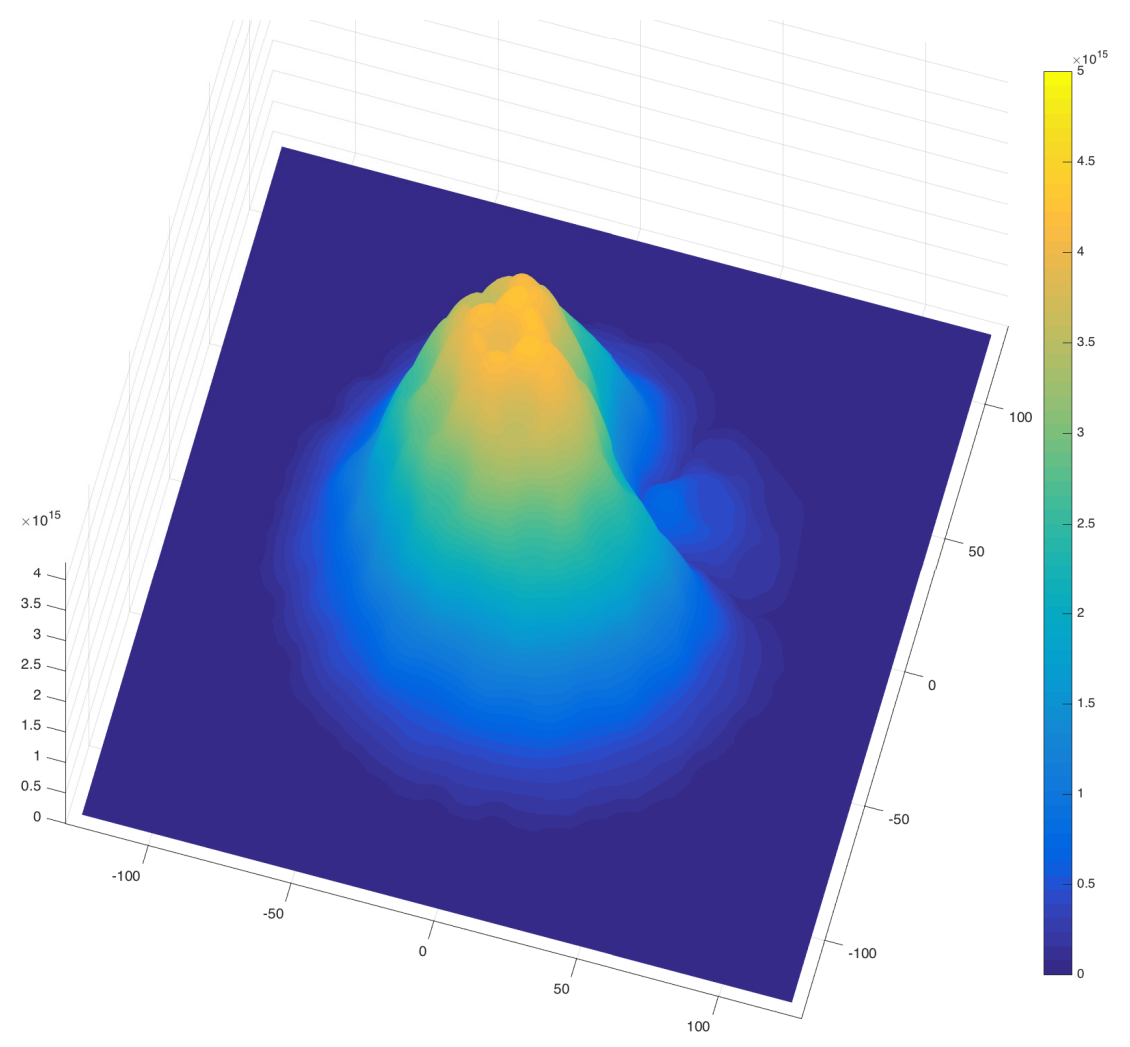

Figure 25. Fast and thermal-neutron flux map for FASTER design.

Figure 26 shows the fission-power and thermal-flux distribution in the power-generating assemblies. The fission power is shown with the "hot" shades, i.e., yellow and red, whereas the thermal flux is shown in "cool" shades, i.e., blue. The power profile in the FASTER design is largely peaked in the center of the active core the peaking factor is about 1.4 for the fresh core. Maximum assembly power density is about $800 \mathrm{~W} / \mathrm{cm}^{3}$, which correlates to a linear power of about $36 \mathrm{~kW} / \mathrm{m}$. The inter-assembly pin power peaking factor for the central fuel assemblies is about 1.1 to 1.2. The fuel assemblies next to the canned beryllium moderating assembly region show pin power peaking factors as high as 1.5 ; however, the average assembly linear power in these regions range between 13 and $29 \mathrm{~kW} / \mathrm{m}$, where the peak linear powers are 20 to $34 \mathrm{~kW} / \mathrm{m}$, respectively.

Pin power peaking factors in the fuel assemblies next to moderating assembly region (Locations B and $\mathrm{H}$ in Figure 23) are illustrated in Figure 27. The maximum power peaking factors are 1.25 and 1.52, respectively. The peak linear power in these locations is 24 and $20 \mathrm{~kW} / \mathrm{m}$. Even though the pin power peaking factors are not an issue due to the low power density in these regions, the skewed burnup profile due to the large power peaking could introduce some difficulties in the fuel management. These could be prevented by introducing small amounts of a thermal neutron absorber, such as boron, in the HT9 reflector located between the fuel assemblies and the canned beryllium moderating assemblies. 


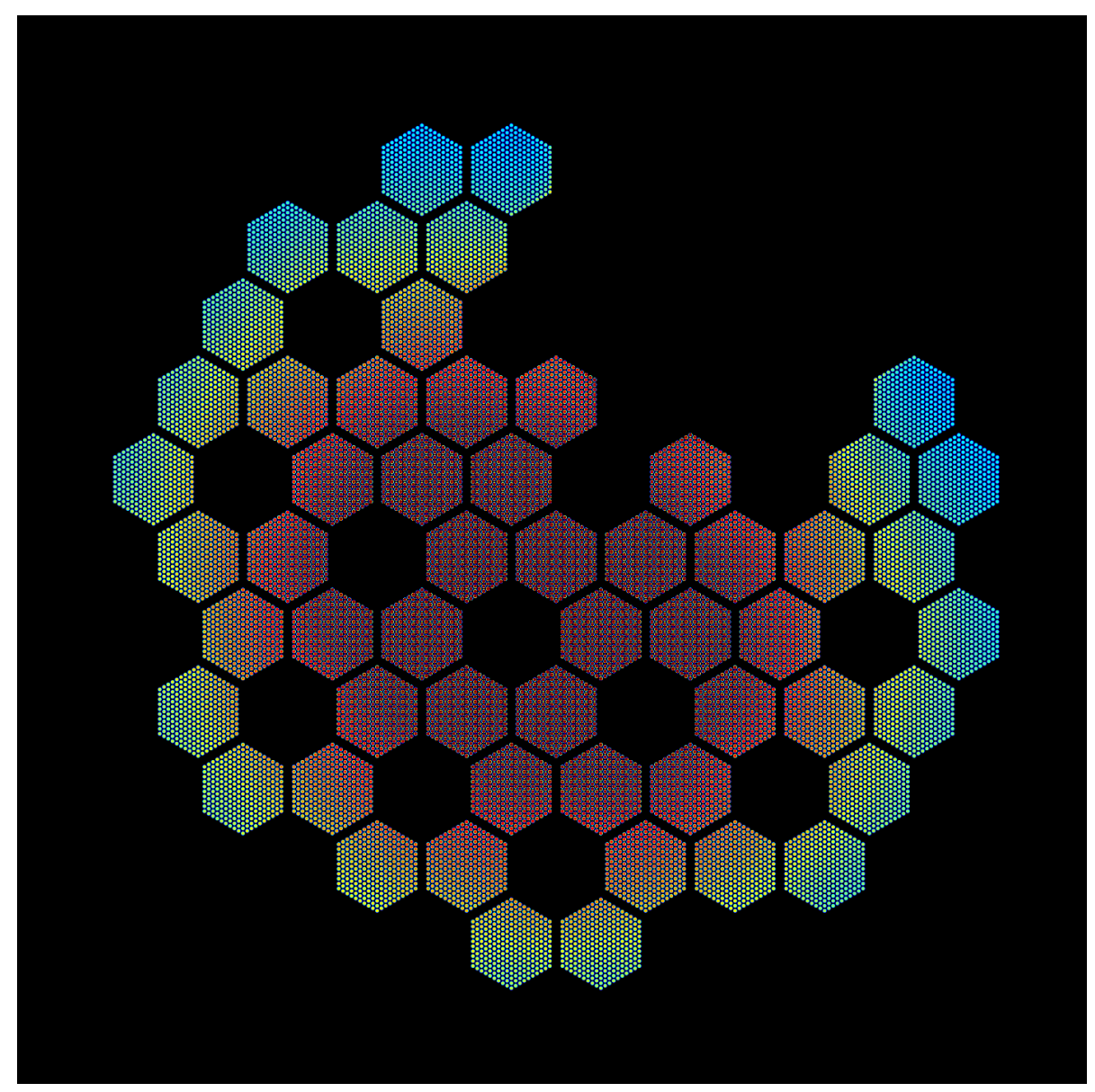

Figure 26. Fission power ("hot" shades - red and yellow) and thermal flux ("cold" shades - blue) distribution.
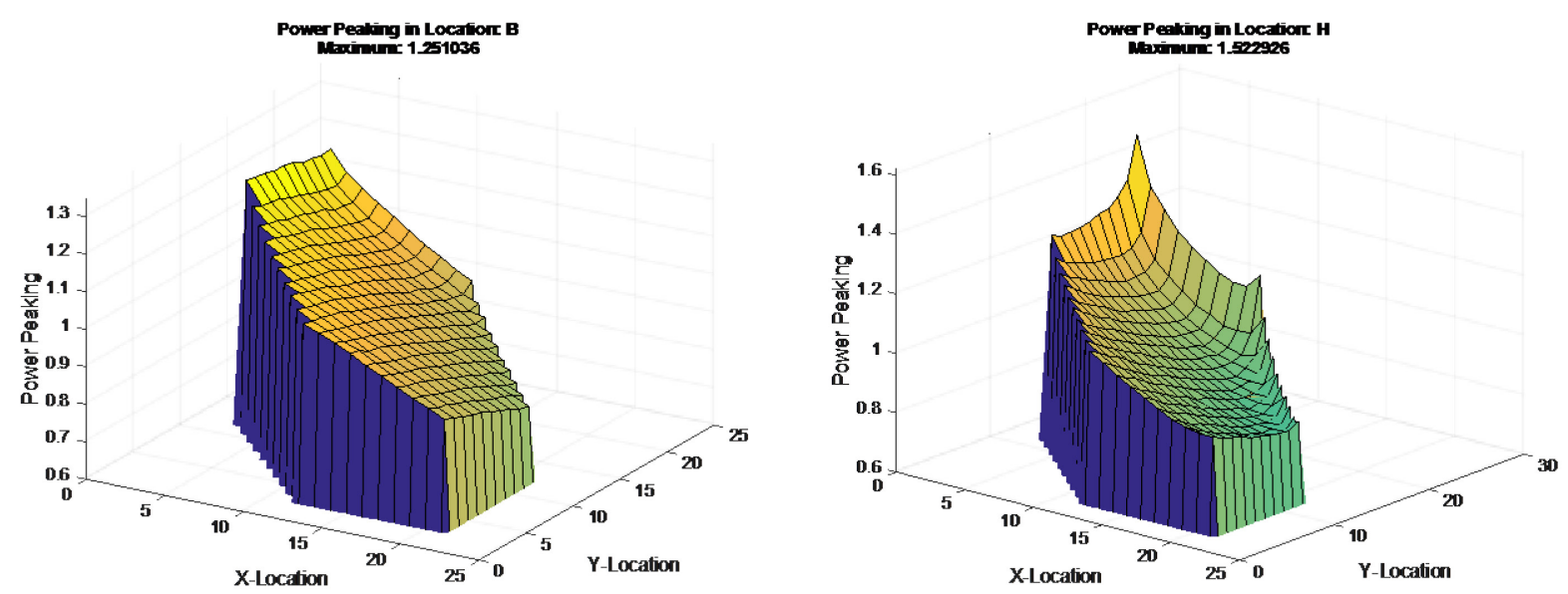

Figure 27. Power peaking factors per pin in the fuel assemblies in Locations B (left) and H (right), as shown in Figure 23. 
Figure 28 shows the average radial fast and thermal flux profiles over the 30 -dgree slices, $\phi_{1}, \phi_{2}$ and $\phi_{3}$, as shown in Figure 23. The flux profile over the slice $\phi_{3}$ is symmetric from the center or the core, i.e., $\mathrm{r}=0 \mathrm{~cm}$. However, the flux profile over the other two slices is not symmetric due to the presence of the moderating assemblies. The effects of the moderating assemblies, i.e., reduction of the fast flux and the shift of the flux profile, are also shown in Figure 28, when the flux profiles over all three slices are compared.

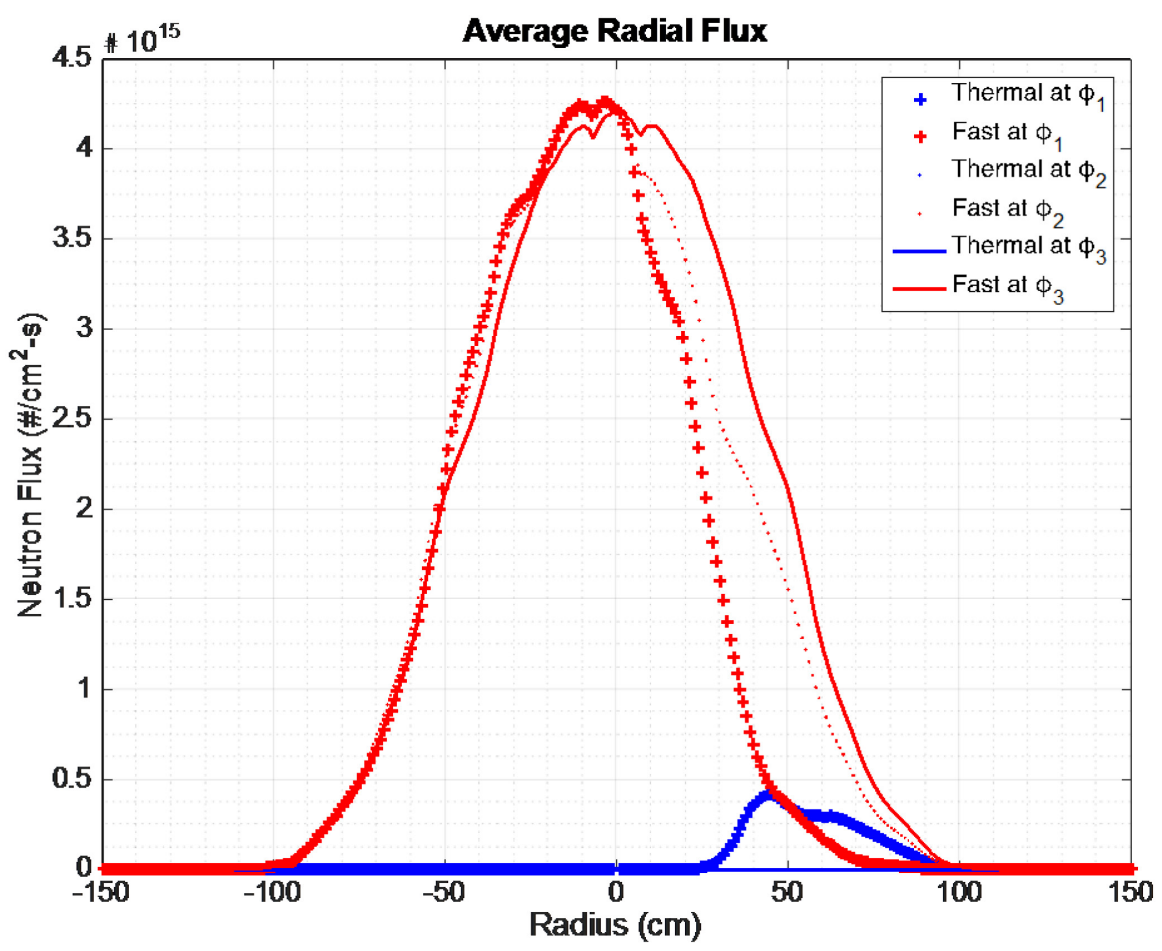

Figure 28 . The axially averaged radial flux profiles tallied in different 30 -dgree slices, as shown in Figure 23.

The fuel-smeared density in the FASTER design is selected to be $85 \%$ instead of $75 \%$, which is conventionally used for metallic fuel due to the low burnup of the fuel. Even though the irradiation swelling, and therefore the internal stress on the cladding applied by fuel, will be less important than a typical metallic fuel with high burnup, the $85 \%$ smeared-density fuel is not well tested and qualified [29]. Therefore, the FASTER design was also analyzed with $75 \%$ fuel smeared density without making any other change. The resulting multiplication factor for fresh core is $0.97704 \pm 0.00015$, i.e., the difference between 85 and $75 \%$ smeared-density fuel is about $7,000 \mathrm{pcm}$. If the use of $85 \%$ smeared-density fuel is unacceptable, the design needs to be changed to accommodate more fuel, which might result in increasing the total power to achieve similar performance in flux values. However, instead of changing the geometry of the design, additional fissile material could also be accommodated by increasing the ${ }^{235} \mathrm{U}$ enrichment in the fuel. 


\subsection{Assessment Summary}

It was found that a very high fast flux, about $5.0 \times 10^{15} \mathrm{n} / \mathrm{cm}^{2}-\mathrm{s}$, is achievable in large volumes. A high thermal flux is also achievable by making use of Zircaloy-2 canned beryllium assemblies. However, the thermal flux values presented in this report do not correspond to ANL results in [27,28], which might be due to the assumed volume fraction of beryllium, coolant, and/or Zircaloy-2 in the analysis. Even though no thermal-fluid analysis was performed, no issues are expected in that area. Although it is not crucial, a small amount of thermal neutron absorber could be added to the HT9 reflector between the moderating assemblies and the fuel assemblies to prevent the thermal-neutron diffusion to the fuel assemblies and the resulting power peaking.

\section{SUMMARY AND CONCLUSIONS}

Work was undertaken at INL from April 2016 to January 2017 to analyze options for neutronically designing a versatile test reactor. Results related to KNK-II and PRISM reactor designs are presented. Alternatives to the VCTR design are presented as well as a neutronic parametric study to assess the minimum power requirement needed for a ${ }^{235} \mathrm{U}$-metal-fueled fast-test reactor capable of generating a fast $(>100 \mathrm{keV})$ flux of $4.0 \times 10^{15} \mathrm{n} / \mathrm{cm}^{2}$-s at the test location. Results regarding a fundamental characteristic of test reactors, namely DPA in test samples, and finally the INL assessment of the ANL fast test reactor design, FASTER, are presented.

The KNK project has very little to offer in terms of data related to a pure coupled reactor. However, it could be seen as an example of the VCTR "booster" concept with a fast-test zone and thermal driver. KNK-II has two significant properties related to VCTR: (1) the demonstration of the transition from one pure thermal reactor to a fast neutron reactor in the same vessel and (2) demonstration of the operation of a thermal-neutron reactor with sodium cooling and with a solid zirconium hydride moderator.

KNK-II is a two-zone core with 29 fuel elements that produced $58 \mathrm{MW}$ of power. The driver zone of KNK-II includes fuel assemblies with solid moderator pins to provide reactivity. From the Avery's coupling coefficients, it was deduced the moderator pins increase the reactivity of the driver zone. The neutrons born in the region with moderated driver fuel assemblies cause more fission in the region with driver-fuel assemblies without moderator pins than the neutrons born in that region, even though the moderated driver-fuel assemblies have 30\% lower fuel enrichment than the ones without moderator pins.

The effect of the solid moderator pins is also quantified by analyzing the KNK-II third core by simply replacing the $\mathrm{ZrH}_{1.6}$ with stainless steel, i.e., no moderation within the driver-fuel assemblies. The effect of the moderation within the driver-fuel assemblies is about 3,500 pcm, which confirms the conclusions derived from the Avery's coupling coefficients.

The PRISM power plant is a sodium-cooled fast-neutron-spectrum reactor designed by GE. An extensive NRC pre-application review was performed on the PRISM design between 1987 and 1994. The PRISM reactor design that underwent the NRC pre-application review employs UPuZr alloy metal fuel with internal and radial blankets. During the DOE ATDR study conducted in 2015 and 2016, GE Hitachi presented a sodium-cooled fast-reactor (PRISM MOD-A) concept based on original PRISM design. It is suggested that the PRISM demonstration reactor would start up on UZr fuel and can be followed by UPuZr fuel.

The analysis of the PRISM equilibrium core showed that a peak fast flux larger than $2.0 \times 10^{15}$ $\mathrm{n} / \mathrm{cm}^{2}-\mathrm{s}$ is achievable, while the peak linear power is about $30 \mathrm{~kW} / \mathrm{m}$. The power fraction in the driverfuel assemblies is about $75 \%$ at the beginning of the equilibrium cycle and drops to $69 \%$ at the end of the equilibrium cycle.

The PRISM MOD-A design was also analyzed using the driver-fuel assembly, reflector, and shieldassembly characteristics of the original PRISM design, because this information is not given in the PRISM MOD-A report. LEU metal fuel in the form of $\mathrm{U}-10 \% \mathrm{Zr}$ was modeled in the driver fuel; however, 
two different enrichments are assumed in different zones: $19 \%$ enriched in Zone 1 and $10 \%$ enriched in Zone 2. Both fuel types were assumed to have $75 \%$ smear density. The fresh core in the model contains about 6.3 tons of uranium (of which 1.2 tons is ${ }^{235} \mathrm{U}$ ) and about 5.3 tons of uranium (of which 0.53 tons is ${ }^{235} \mathrm{U}$ ) in Zones 1 and 2, respectively.

The analysis of the fresh core showed that a peak fast flux $(\mathrm{E}>0.1 \mathrm{MeV})$ of about $2.5 \times 10^{15} \mathrm{n} / \mathrm{cm}^{2}-\mathrm{s}$ is achievable while the peak total flux is $3.5 \times 10^{15} \mathrm{n} / \mathrm{cm}^{2}$-s. The peak linear power in the core is about $26 \mathrm{~kW} / \mathrm{m}$. The preliminary depletion calculation showed that such a core composition would achieve a 15-month cycle length, with three-batch loading leading to an average fuel burnup of about $50 \mathrm{GWd} / \mathrm{tHM}$.

The VCTR concept was also analyzed. Two approaches to the coupling concept are described in the literature, with one approach having the main purpose of minimizing the power and fissile inventory and the other approach having the main purpose of minimizing the flux gradients. The reference VCTR design uses LEU for the boosted case, producing $3.5 \times 10^{15} \mathrm{n} / \mathrm{cm}^{2}$-s peak fast flux at the test location at $270 \mathrm{MW}$ of power. A plutonium and LEU core beside the LEU-only core was analyzed. The use of plutonium in the driver-fuel assemblies could not only help to increase the peak fast flux but could also help to increase the volume of test locations by providing additional reactivity.

The use of plutonium in the VCTR design not only improves the performance of the core $\left(4.0 \times 10^{15}\right.$ $\mathrm{n} / \mathrm{cm}^{2}$-s vs. $3.5 \times 10^{15} \mathrm{n} / \mathrm{cm}^{2}$-s peak fast flux) but also allows increases the test volumes (three versus one fast-spectrum closed loop). The thermal neutrons from the graphite reflector surrounding the boosterfuel assemblies cause high power peaking in the fuel pins next to the reflector. Therefore, fuel enrichment zoning is required in this region. The thermal neutrons are captured by the outermost fuel pins; therefore, the inner part of the booster-fuel assemblies has a fast-neutron spectrum. The purpose of using stainlesssteel reflector between the driver- and booster-fuel assemblies is to provide enough space for secondary control (shutdown) systems.

The booster-fuel assemblies provide reactivity for allowing the use of LEU in this region, thus reducing the required plutonium content. If enough plutonium is available for the entire operation of such a test reactor, then the same or better performance could be achieved using only driver-fuel assemblies, i.e., without using booster-assembly or coupled-core concepts. But then the versatility characteristic will be lost.

However, if the neutron moderation were realized within the fuel assemblies by introducing moderator pins $\left(\mathrm{ZrH}_{1.6}\right.$, for example), as in the KNK II case, the amount of fuel pins that is exposed to the thermal spectrum would be increased, thus increasing the total reactivity of the system. The peak fast flux $(\mathrm{E}>0.1 \mathrm{MeV})$ at the central and peripheral closed-loop locations is $3.5 \times 10^{15} \mathrm{n} / \mathrm{cm}^{2}$-s and $2.0 \times 10^{15}$ $\mathrm{n} / \mathrm{cm}^{2}$-s, respectively. The peak thermal flux $(\mathrm{E}<0.625 \mathrm{eV})$ is $0.8 \times 10^{15} \mathrm{n} / \mathrm{cm}^{2}$-s. Even though bringing the moderation inside the fuel assembly increases the reactivity, the reactivity swing also increases due to the increased power peaking in these assemblies. If the optimum moderation is used, the linear power peak per fuel pin increases significantly. Therefore, an under-moderated fuel assembly was designed. Also, the number of moderated-fuel assemblies increased to lower the power peaking. Even though it is not optimized, the VCTR-LEU design with the moderating booster assemblies has a total of $10 \%$ less HM than the reference VCTR-LEU design without the moderator pins, which corresponds to about $7 \%$ less ${ }^{235} \mathrm{U}$. The use of moderator solid pins might significantly reduce the fuel inventory if optimized further. Note that these designs are not optimized, and the results shown here are preliminary.

A parametric study has been conducted to assess the minimum power requirement needed for a ${ }^{235} \mathrm{U}$ metal-fueled fast-test reactor capable of generating a fast $(>100 \mathrm{keV})$ flux of $4.0 \times 10^{15} \mathrm{n} / \mathrm{cm}^{2}$-s at the test location. The parameter field was related to different forms and enrichments for the fuel.

Note that it was possible to achieve the desired fast-flux level as the result of a sharp radial gradient in the core region. It still remains to be seen if such a gradient is acceptable in a fuel management strategy. 
Indeed, in view of the fact that it is a test reactor design effort, it is possible to foresee a requirement for the power peak radial factor that is less stringent than those typically in place for power-generating reactors. The full spectrum of possible variable parameters was not studied, and a further comprehensive investigation is needed to better assess the booster LEU core option.

It is important to quantify the radiation damage that a test sample would receive in a test reactor. To evaluate radiation damage, a fundamental parameter that characterizes lattice displacement events is required. DPA, the number of times that an atom is displaced for a given fluence, has been used to compare radiation damage by different radiation sources.

The DPA for a 0.5 -cm-radius cylinder located at the center of a central fast-spectrum test loop made of both ${ }^{56} \mathrm{Fe}$ and stainless steel was estimated for the reference LEU-VCTR design. The average total flux at the test location is $3.5 \times 10^{15} \mathrm{n} / \mathrm{cm}^{2}$-s. The DPA achieved in a year with $80 \%$ availability factor, i.e., 300 days of total irradiation time, is about 25 for natural iron and about 26 for the stainless steel.

The neutrons with higher energies are more significant in terms of the DPAs accumulated in a test subject. The damage cross section at higher neutron energies $(\mathrm{E}>1 \mathrm{keV})$ is 2 to 3 orders of magnitude larger than the damage cross section at lower energies. To assess the effect of the different neutron spectra on the accumulated DPA on a test sample, a simple calculation was performed with super cells (two rings of assemblies) of different core concepts: a typical MHTGR, LWR, FAST reactor, and VCTR.

In a typical LWR spectrum, the neutron flux above $1 \mathrm{MeV}$ accounts for about 40 to $50 \%$ of the neutron flux above $0.1 \mathrm{MeV}$, whereas it accounts for about 15 to $20 \%$ in a typical fast reactor spectrum. The fast neutron peaks are at about 1 and $0.1 \mathrm{MeV}$ in a typical LWR and fast reactor, respectively. The total DPA per year in typical fast-reactor concepts is about 10 times larger than the DPA accumulated in a typical LWR concept, while the DPA per year is about 60 times larger than it is in a typical MHTGR.

ANL developed a fast-test reactor concept, FASTER, as a part of the ATDR study under the ART program during 2015 and 2016. FASTER is a passively safe, sodium-cooled, fast-spectrum test reactor that relies on proven technologies. The main desired features of the FASTER concept are a very high fast flux to complement current testing capabilities; many test locations, large test volumes, and high thermal flux.

It was found that a very high fast flux, about $5.0 \times 10^{15} \mathrm{n} / \mathrm{cm}^{2}-\mathrm{s}$, is achievable in large volumes. A high thermal flux is also achievable by making use of Zircaloy- 2 canned beryllium assemblies. However, the thermal flux values presented in this report do not correspond ANL results, which might be due to the assumed volume fraction of beryllium, coolant, and/or Zircaloy-2 in the analysis. Even though no thermal-fluid analysis was performed, no issues are expected in that area. Although it is not crucial, a small amount of thermal neutron absorber could be added to the HT9 reflector between the moderating assemblies and the fuel assemblies to prevent the thermal-neutron diffusion to the fuel assemblies and the resulting power peaking.

The fuel-smeared density in the FASTER design is selected to be $85 \%$ instead of $75 \%$, which is conventionally used for metallic fuel due to the low burnup of the fuel. Even though the irradiation swelling, and therefore the internal stress on the cladding applied by fuel, will be less important than a typical metallic fuel with high burnup, the $85 \%$ smeared-density fuel is not well tested and qualified. Therefore, the FASTER design was also analyzed with $75 \%$ fuel-smeared density without making any other change. The resulting multiplication factor for fresh core is $0.97704 \pm 0.00015$, i.e., the difference between 85 and $75 \%$ smeared-density fuel is about $7,000 \mathrm{pcm}$. If the use of $85 \%$ smeared-density fuel is not acceptable, the design needs to change to accommodate more fuel, which might result in increasing the total power to achieve the similar performance in flux values. However, instead of changing the geometry of the design, additional fissile material could also be accommodated by increasing the ${ }^{235} \mathrm{U}$ enrichment in the fuel. 


\section{REFERENCES}

[1] Idaho National Laboratory, VCTR: A Versatile Coupled Test Reactor Concept, INL/EXT-16-38852, Rev. 1, May 2016.

[2] M. Salvatores, The KNK Reactor: Experience and Possible Lessons for the VCTR, INL/EXT-16-40157, October 2016.

[3] W. Marth, The History of the Construction and Operation of the German KNK II Fast Breeder Power Plant, KfK 5456, European Fast Reactor Project, November 1994.

[4] INTERATOM Gmbh, KNKII Compact Sodium-Cooled Reactor in the Nuclear Research Center Karlsruhe, 1978.

[5] Stanculescu, A., U. Wehmann, H. Wilhelm, F. Sperber, and W. Feltes, Nuclear Design of the Fast Test Reactor KNK II and Some Aspects of its Operational Behaviour, IAEA-SM-244/51, INTERATOM Gmbh, 1980.

[6] Mausbeck, H. and W. Marth, "Safety-oriented Operating Experience with KNK II," Proceedings of the International Topical Meeting on Fast Reactor Safety, Knoxville, Tennessee, April 21-25, 1985, Vol. I.

[7] Heinecke, J., A. Stanculescu, W. Kathol, and H. Richard, "Operating Experience with KNK II as an Experimental Reactor," International Symposium on Fast Breeder Reactors: Experience and Trends, IAEA, Lyon, France, July 22-26, 1985, Vol. I.

[8] Husken, J., K. Fenneker, J. Singer, W. Zihla, and D. Coors, Auslegungsbericht fur Kernelemente KNK II: Treiberzonelelemente mit Moderator Schutzbedurftiges Firmeneigentum, Technischer Bericht 33.01910.8, INTERATOM Gmbh, October 1979.

[9] Fenneker, K., R. Menssen, E. Ricken, G. West, H. Spenke, F. Sperber, and U. Wehmann, Stab-, Element- und Kernauslegung fur den verlangerten Betrib des Erstkerns der KNK II, Technischer Bericht 33.02587.1, INTERATOM Gmbh, October 1980.

[10] Leppanen, J., Serpent - a Continuous-energy Monte Carlo Reactor Physics Burnup Calculation Code, VTT Technical Research Centre of Finland, August 16, 2016.

[11] Avery, R., “Coupled fast-thermal power breeder reactor," US Patent No: 2,992,982, July 18, 1961 (filed December 10, 1957).

[12] Aufiero, M., G. Palmiotti, M. Salvatores, and S. Sen, "Coupled reactors analysis: New needs and advances using Monte Carlo methodology," Annals of Nuclear Energy, Vol. 98, 2016, pp. 218-225.

[13] INTERATOM Gmbh, "Kompakte Natriumgekuhlte Kernreaktorlage mit schnellen Kern (KNK II Karslruhe), sicherheitsbericht,” INTAT 7501438, 75.01438.5, September 1981.

[14] Bestenreiner, G., K. Fenneker, J. Heinecke, J. Singer, and F. Sperber, Auslegungsbericht fur Kernelemente KNK II/2: Mark II Kranzelemente det Testzone 2.1, 2.2, 2.3, 2.6, 3.1, 3.3 und 3.5, Technischer Bericht 54.04164.+, INTERATOM Gmbh, October 1981.

[15] Fenneker, K., Auslegungsbericht fur Kernelemente KNK II/2: Brennstabe der Testzone mit Brennstoff hoher dichte, Technischer Bericht 54.04214.9, INTERATOM Gmbh, December 1981.

[16] Spenke, H., Kernauslegung fur die 2. Betriebsperiode der KNK II, Technischer Bericht 33.02743.4, INTERATOM Gmbh, September 1981.

[17] Timm, W., KNK II, 3. Kern Auslegungsbericht fur den Kern, Technischer Bericht 54.07541.*, INTERATOM Gmbh, May 1988. 
[18] Tobbe, H., KNK II, 3. Kern: Auslegungsberricht fur Mark-II-Kranzelemente der Testzone NY401 bis NY406, Technischer Bericht 54.07020.4, INTERATOM Gmbh, August 1986.

[19] Ricken, E. and H. Tobbe, KNK II, 3. Kern: Auslegungsberricht fur Treiberzonelemente NU 401 bis 407 (ohne Moderator) und NW 401 bis 421 (mit Moderator), Technischer Bericht 54.07025.3, INTERATOM Gmbh, October 1986.

[20] Tobbe, H., KNK II, 3. Kern: Auslegungsberricht fur Regeltrimmelemente, Technischer Bericht 54.07021.6, INTERATOM Gmbh, January 1987.

[21] Ricken, E., KNK II, 3. Kern: Auslegungsberricht fur die Bruttelemente NR-230-R, NR-231-R, NR-233-D und NR-234-D, Technischer Bericht 54.07630.1, INTERATOM Gmbh, July 1988.

[22] General Electric, PRISM Preliminary Safety Information Document, Vol. I, GEFR-00793, December 1987.

[23] U.S. Nuclear Regulatory Commission, Preapplication Safety Evaluation Report for the Power Reactor Innovative Small Module (PRISM) Liquid-Metal Reactor, Final Report, NUREG-1368, February 1994.

[24] GE HITACHI Nuclear Energy, Demonstration Sodium-Cooled Fast Reactor GE-PRISM, 003N4516, Rev. 2, March 2016.

[25] Organisation for Economic Co-operation and Development/Nuclear Energy Agency, Primary Radiation Damage in Materials, NEA/NSC/DOC(2015)9, 2015.

[26] MacFarlane, R. E., The NJOY Nuclear Data Processing System, Version 2012, LA-UR-12-27079, February 12, 2015.

[27] Argonne National Laboratory, FASTER Test Reactor Preconceptual Design Report - Summary, ANL-ART-40, February 29, 2016.

[28] Heidet, F. and C. Grandy, "FASTER - Concept Overview," Presentation at Oak Ridge National Laboratory, August 4, 2016.

[29] Hayes, S., "Startup Fuel for the ATDR," White Paper, Idaho National Laboratory, January 2016. 


\section{Appendix A}

\section{The Damage and Gas Production Cross-Section Library Generation for Serpent2 Using NJOY}




\section{Appendix A}

\section{The Damage and Gas Production Cross-section Library Generation for Serpent2 Using NJOY}

Serpent 2 reads continuous-energy cross sections from ACE format data libraries. The interaction physics is based on classical collision kinematics, evaluated nuclear data file (ENDF) reaction laws and probability table sampling in the unresolved resonance region. ACE format cross-section libraries based on JEF-2.2, JEFF-3.1, JEFF-3.1.1, ENDF/B-VI.8, and ENDFB/B-VII evaluated data files are included in the installation package of Serpent1. Interaction data are available for 432 nuclides at six temperatures between 300 and 1,800 K. Thermal bound-atom scattering data are included for light and heavy water and graphite. Because the data format is shared with MCNP, any continuous-energy ACE format data library generated for MCNP can be used with Serpent2as well.

The following is a sample input for ACE library generation, including displacement per atom and gas production cross sections using NJOY code system for ${ }^{56} \mathrm{Fe}$ isotopes.

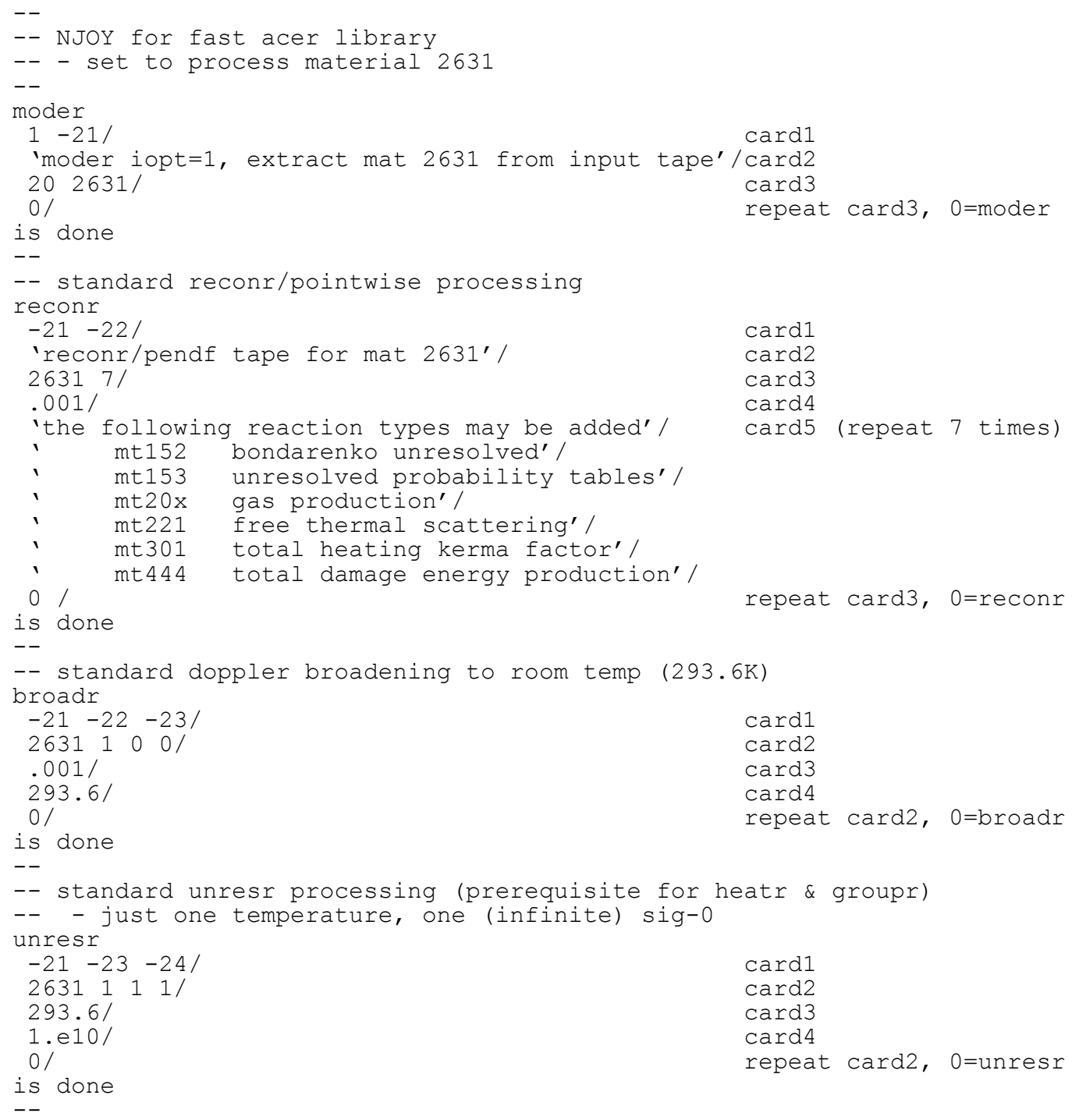




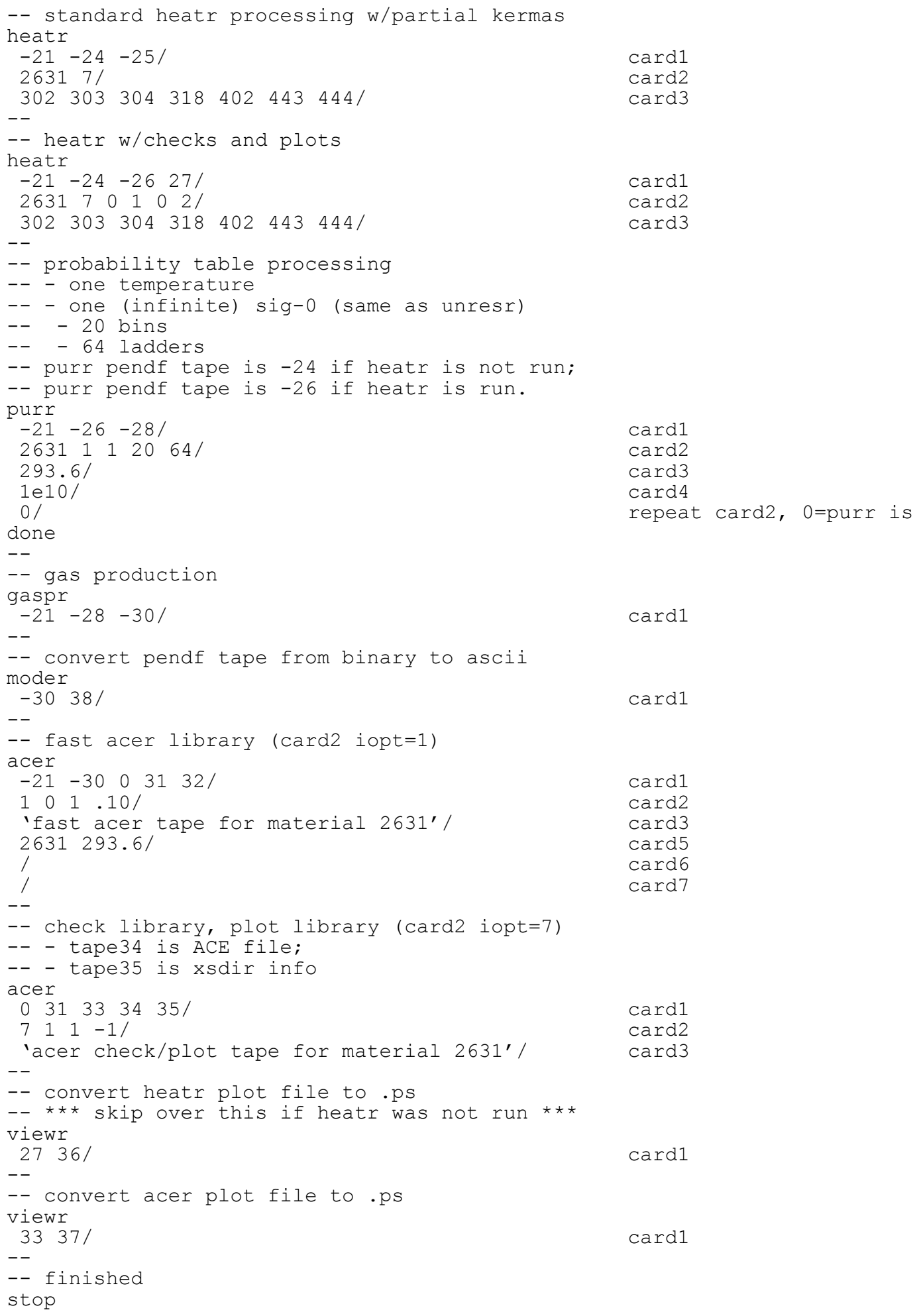

$\operatorname{card1}$

card2

card3

card1

card2

card3

card1

card2

card3

card4

repeat card2, $0=$ purr is

card1

cardl

card1

card2

card3

card5

card6

card7

cardl

card2

card3

cardl

card1 